Démocratie délibérative, démocratie débattante, démocratie participative

\title{
La dynamique des relations de confiance et d'autorité au sein de la démocratie dite " participative » et « délibérative "
} Un exemple typique : le Débat Public « loi Barnier » en Provence-Côte d'Azur (1998)

\section{Alban Bouvier}

\section{OpenEdition}

\section{Journals}

Édition électronique

URL : http://journals.openedition.org/ress/97

DOI : $10.4000 /$ ress. 97

ISSN : $1663-4446$

Éditeur

Librairie Droz

Édition imprimée

Date de publication : 1 février 2007

Pagination : 181-230

ISBN : 978-2-600-01114-3

ISSN : 0048-8046

\section{Référence électronique}

Alban Bouvier, «La dynamique des relations de confiance et d'autorité au sein de la démocratie dite " participative » et « délibérative » », Revue européenne des sciences sociales [En ligne], XLV-136 | 2007, mis en ligne le 01 février 2010, consulté le 01 mai 2019. URL : http://journals.openedition.org/ress/97 ; DOI : 10.4000/ress.97 


\title{
LA DYNAMIQUE DES RELATIONS DE CONFIANCE ET D'AUTORITÉ AU SEIN DE LA DÉMOCRATIE DITE «PARTICIPATIVE» ET «DÉLIBÉRATIVE» Un exemple typique: le Débat Public «loi Barnier» en Provence-Côte d'Azur (1998) ${ }^{1}$
}

\author{
I. UNE INTERPRÉTATION MINIMALE \\ DE LA DÉMOCRATIE DE PROXIMITÉ
}

Les démocraties occidentales sont toutes, à des degrés divers et sous des formes diverses, des démocraties représentatives. Or, si les utopies révolutionnaires ont disparu progressivement, s'effondrant avec la chute du mur de Berlin et celle des puissances sous domination du pouvoir soviétique, si les partis d'extrême-gauche classiques ont eux-mêmes quasiment disparu de la planète, les pouvoirs de ces démocraties sont néanmoins régulièrement confrontés à des difficultés considérables dans l'application de leurs décisions, que ces pouvoirs soient de droite ou de gauche et qu'ils soient libéraux ou républicains. Comme tous les pouvoirs qui ne reposent pas sur la force brute (ou, ce qui revient au même, sur la terreur), les démocraties sont par nature fragiles puisqu'elles reposent sur la seule légitimité qu'elles inspirent, laquelle, de quelque type qu'elle soit, est sujette à usure et même à renversement ${ }^{2}$. A cette fragilité structurelle de l'autorité politique

1 Les idées exposées dans cet article, différent dans son axe directeur de la communication faite au colloque d'Aix-en-Provence de mai 2004 («Limites cognitives du débat public»), où j'avais notamment tiré parti de discussions avec Jon Elster et James Bohman, ont été présentées en différentes autres occasions. L'une des premières versions a été prononcée à l'invitation de Frédéric Nef à Rennes le 17 Novembre 2001. Une version intermédiaire a fait l'objet d'une communication au séminaire du département de philosophie de l'Université Laval à Québec, le 8 Novembre 2004. Le choix initial de la thématique propre à l'article présent vient toutefois d'une invitation de Pasquale Pasquino à participer à une journée d'études sur «Déférence, autorité, légitimité», organisée par lui-même et Vincent Descombes à l'EHESS de Paris le 31 janvier 2003, puis à un workshop sur le même thème à Rome le 9 mars 2005, où je n'ai pu finalement me rendre. Une version proche de celle que je présente ici a été discutée lors du séminaire du laboratoire «Communication et Politique», le 17 janvier 2005 à l'invitation de Marianne Doury. J'ai tiré parti aussi d'un échange très antérieur avec Bernard Manin à l'occasion d'une table ronde lors d'une journée de philosophie morale organisée par Monique Canto-Sperber et Pierre Manent à l'EHESS en Mai 2001. Les encouragements de David Wiggins ainsi que les critiques amicales de Ruwen Ogien lors de cette journée m'avaient incité à approfondir ces questions. Je remercie ce dernier ainsi que Philippe Urfalino pour leur relecture attentive de l'avant-dernière version. Le résultat le plus évident de ces nombreuses versions est un texte fort long, comportant la matière de plusieurs articles - que je crois néanmoins étroitement articulés - et sollicitant malheureusement probablement outre mesure l'attention du lecteur.

2 Cf. Rousseau (1964 [1762]): «Le plus fort n'est jamais assez fort pour être toujours le maitre s'il ne transforme sa force en droit et l'obéissance en devoir» (Contrat Social, I, chap. 3). Il n'y a pas 
comparée à la force brute du pouvoir pur s'ajoutent des faiblesses plus conjoncturelles liées au degré de confiance que ces détenteurs du pouvoir inspirent; celui-ci n'est ainsi, comme on sait, guère élevé en France et a fortiori en Italie, pour des raisons au demeurant fort diverses ${ }^{3}$. L'absence de grands partis politiques d'extrême-gauche ne signifie pas la disparition d'idées alternatives mais celles-ci, qui s'inscrivent actuellement le plus souvent dans le cadre très global d'un altermondialisme, restent très indéterminées lorsqu'elles ne se présentent pas comme de simples aménagements (en général dans le sens de davantage de régulation des démocraties existantes) mais comme des alternatives radicales. L'idée de larges débats, au niveau international et «global» $\rangle^{4}$ (forums sociaux du type de Porto Alegre), lieux d'expression contestataire des gouvernés répondant aux rencontres régulières, elles-mêmes internationales, des décideurs mondiaux (notamment à Davos), est une idée très populaire en ce contexte. Mais l'idée de débats est tout aussi populaire à l'autre extrémité de la gestion politique, i.e. à l'échelon local, les échelons intermédiaires semblant avoir fait la preuve de leur insuffisance; et Porto Alegre fait à nouveau figure de modèle, non plus pour les forums mondiaux qui y sont organisés, mais pour l'originalité de sa gestion municipale ${ }^{5}$.

Je m'intéresserai exclusivement, dans cet article, à un type de débats locaux différents de ceux mis en place par la municipalité de Porto Alegre, mais sans perdre de vue les enjeux les plus généraux, celui de l'éventuelle recherche de solutions politiques alternatives aux démocraties existantes dans un univers postmarxiste et post-communiste (Habermas, 1976).

De nouvelles formes de démocratie de proximité se développent en effet dans différents pays occidentaux, notamment en France, sous la forme de conseils de quartiers - Porto Alegre, dans le Sud-Est du Brésil, pouvant être perçu comme élargissant au niveau d'une ville le type d'expériences qui se mène ailleurs au seul niveau des quartiers ${ }^{6}$. Mais il existe aussi d'autres formes de démocratie de proximité, concernant en particulier les projets d'aménagement du territoire d'intérêt national ou régional (en Canada, en France, aux Etats-Unis), aux conséquences directes sur les riverains. Ces innovations juridico-politiques consistent en l'organisation par l'Etat de débats publics au niveau local ou régional destinés à

grand-chose à changer à l'énoncé rousseauiste si ce n'est son caractère indéterminé - que peut vouloir dire «toujours»? - et excessif, car il a existé des tyrans qui ont durablement exercé la force brute sans être pour autant renversés par ceux-là mêmes qui subissaient ce pouvoir.

3 Pour l'esquisse d'une comparaison internationale récente, cf. Lipset (1996). Crozier, Huntington et Watanuki (1975), dans un rapport fameux, cité par G. Lavau et O. Duhamel (1985, p. 88) situaient - avec vraisemblance - dans les valeurs modernes d'égalité et d'individualisme la source spécifique la plus profonde de la «déligitimation de l'autorité et [de la] perte de confiance dans le leadership» caractéristique des sociétés modernes occidentales. Un constat analogue peut être fait dans d'autres domaines de la vie sociale: cf. A. Renaut (2004). Habermas $(1976,1978)$ mettait en cause de façon plus globale le capitalisme avancé.

4 L'anglais dit «globalisation». Le terme suggère non seulement que le «global» occupe un pôle opposé au «local», mais qu'il convient de toujours les concevoir en relation l'un par rapport à l'autre.

5 Une des spécificités de la municipalité de Porto Alegre est précisément, entre autres, d'avoir associé local et global. Pour une clarification des enjeux, cf. le très utile Gret et Sintomer (2002).

6 Sur ces associations de quartier en France, voir notamment Cefaï et Lafaye (2001). Pour une comparaison avec Porto Alegre, cf. Gret et Sintomer (2002). 
permettre l'expression des riverains en question. Certains d'entre ces débats sont spécialement intéressants parce qu'y existe plus explicitement qu'ailleurs une contrainte d'argumentation - on verra bientôt en quel sens précis. Les enjeux de ces débats peuvent apparaître au premier abord assez triviaux puisqu'ils ont toujours une composante technique très marquée, tandis qu'on n'y parle guère des «grands problèmes de société» ni des questions d'ordre éthique ou religieux, en tout cas directement (comme le droit à l'euthanasie des grands handicapés ou le droit de porter le voile islamique), mais ces débats - dont on pressent que l'objet pourrait aisément être étendu à des questions substantielles de la vie sociale (pertinence de la construction d'une mosquée ou d'une synagogue dans un quartier périphérique, par exemple) - conduisent, de toute façon, à soulever de façon très précise des questions qui, elles, ne sont pas du tout triviales puisqu'elles touchent à la nature même de l'autorité et de la confiance politiques.

C'est, en France, l'objet de la loi Barnier de 1995 sur l'aménagement du territoire, prolongée par la loi de 2002 sur la démocratie de proximité, que de mettre en place de tels débats. Un des buts originaires de ces innovations n'était que d'ordre très pragmatique et visait à formaliser des procédures prises peu auparavant dans l'urgence ${ }^{7}$. Il s'agissait surtout d'essayer de modifier les représentations collectives des riverains réticents à l'égard de projets d'aménagement touchant à leur environnement proche par des campagnes d'information originales, puisque fondées sur la structure du débat, destinées à écarter les craintes infondées de la population et à prévenir par là une opposition plus déterminée susceptible, par des voies légales ou illégales, d'ajourner, voire de mettre définitivement en péril la réalisation du projet, comme cela avait été le cas lors de projets similaires ${ }^{8}$. A l'usage, un but secondaire et légèrement plus ambitieux, en tout cas moins défensif, est apparu, celui de tirer parti des objections et suggestions éventuelles des riverains, surgies au cours du débat, pour transformer et éventuellement améliorer le projet, évolution dont témoigne la loi de 2002, puisqu'elle reconnaît explicitement à ces débats un pouvoir consultatif.

Les innovations juridiques que je viens d'évoquer apparaissent intelligibles d'un point de vue rationaliste classique, puisque non seulement elles entendent asseoir la légitimité des décisions politiques en vue de leur application effective en tenant compte des réticences des riverains (rationalité qu'on pourrait dire «adaptative»), mais en outre elles cherchent à y parvenir au travers d'un échange réglé d'arguments (rationalité qu'on pourrait dire «logique» lato sensu dans la mesure où il s'agit à la fois d'éprouver la cohérence logique des arguments et leur validité empirique), le tout dans le cadre de démocraties de type représentatif?.

\footnotetext{
7 Jean-Louis Bianco émit une circulaire en 1992, dite «circulaire Bianco», pour organiser en pleins remous sociaux un débat destiné à désamorcer les conflits engendrés par la mise en place de la construction de la ligne ferroviaire du TGV Sud-Est.

8 L’Etat espérait aussi, semble-t-il, éprouver de façon générale un autre mode de «gouvernance», sa gestion de la restructuration des PTT sur un mode traditionnel s'étant révélée socialement très coûteuse.

9 C'est cependant un rationalisme déjà quelque peu sophistiqué qui est requis, puisqu'il requiert que soient prises en compte des relations comme celles d'autorité et de confiance, problématiques pour quiconque voudrait régler ses actions sur la seule raison propre. C'est ce défi précis, au cœur des débats tant sur les limites des Lumières en général que de la théorie dite du choix rationnel en particulier, qu'entend circonscrire cet article (cf. III ${ }^{\mathrm{e}}$ partie).
} 
Mais l'interprétation qui précède - en terme de rationalisation de la vie politique - paraîtra très minimaliste au regard d'un certain nombre d'interprétations tantôt explicites, tantôt (et plus souvent encore) diffuses, mais, en certains contextes, dominantes. Ces interprétations caractérisent souvent, en effet, les débats publics en question comme des expressions de la démocratie participative, voire - notamment avec la vogue, en France, de l'idée habermassienne de politique délibérative (1997b, 1998) - de la démocratie délibérative (conçue comme variété de démocratie participative $)^{10}$.

Je voudrais montrer que ces concepts ont un contenu de sens passablement flottant ou, plus exactement, que les désignations de «démocratie participative» et de «démocratie délibérative» se révèlent renvoyer l'une et l'autre, dès lors que l'on prend la peine d'en circonscrire les divers usages, à des concepts passablement différents; on peut généraliser le constat aux usages étrangers, notamment à ceux de l'anglais, la vraie lingua franca philosophique et scientifique, participatory democracy, par exemple, ne renvoyant pas forcément exactement au même concept que notre «démocratie participative».

Or, d'un côté, dans l'un des usages les plus fréquents de l'expression «démocratie participative», le pouvoir de décision est inhérent au concept de participation auquel renvoie l'expression - ce qui n'est pas vrai de tous les usages du terme «participation ${ }^{11}$. De l'autre, et ce point est encore plus important, le pouvoir de décision est également inhérent au concept de délibération dans les usages classiques, philosophiques (aristotéliciens) et juridiques, auquel renvoient les termes délibération, délibératif, «délibérant» - en français - tout autant que les termes «deliberation» (en anglais) et «déliberation» (en traduction française) chez Rawls (1987) ${ }^{12}$ - alors que ce n'est pas du tout vrai de l'usage régulier de l'expression deliberative democracy dans la littérature post-habermassienne ${ }^{13}$. Il y a là, à mon sens, une difficulté majeure car, dans les débats dont

${ }^{10}$ Il existe aux Etats-Unis une tradition pratique spécifique de démocratie participative «débattante» (baptisée, abusivement à mon sens, «délibérative»), qui ne doit rien à Habermas. Cf. Gastil et Keith (2005) et l'introduction de ce volume.

11 Je ne me livrerai bien entendu pas à une analyse de tous les usages du terme «participation» en politique ni en sciences politiques; on pourra consulter à ce sujet Memmi (1985), pp. 311-315, mais celui-ci ne prend pas en compte les usages (plus récents) que nous avons à considérer ici.

${ }^{12}$ Manin (2002, p. 43) note très justement que «la théorie rawlsienne n'était pas délibérative, elle l'est devenue [à partir de Libéralisme politique]» (p. 43). Dans la Théorie de la justice, Rawls donne en effet une représentation très «monologique» des choix (il n'y a même pas place pour une délibération avec soi-même). Rawls s'est peu exprimé sur l'idée de démocratie délibérative elle-même (voir cependant «Réponse à Habermas», in Habermas et Rawls [1997], pp. 49-142, notamment p. 51, n.2, p. 63-64, n.19 et pp. 102-103); mais en raison de son évolution considérable et des implications particulières de celle-ci (la délibération est conçue au niveau des Assemblées Constituantes, des Parlements, des Exécutifs, des Cours de Justice, etc., et non pas au niveau des forums informels, i.e. de l'espace public habermassien), John Rawls est donné comme une référence capitale sur le sujet. Voir notamment Bohman, 1997a.

${ }^{13}$ Habermas (1997b [1992]) est, il est vrai, au contraire, explicite: il distingue le processus délibératif, interne aux «procédures démocratiques» institutionnelles classiques, des «processus informels de formation de l'opinion qui se déroulent dans l'espace public» (p. 332). Mais on ne peut pas dire que Habermas mette vraiment ce thème en exergue. Par ailleurs, dans d'autres textes (par exemple, 1992), Habermas est nettement moins clair. 
je parle ici, les participants sont précisément entièrement privés du pouvoir de décision ${ }^{14}$

Certaines des interprétations dominantes, explicites ou plus souvent latentes et diffuses, de la démocratie de proximité, en France ou à l'étranger, sont donc trompeuses eu égard à certains concepts robustes et résistants. Car si l'on fait de la démocratie participative et de la démocratie délibérative, au sens que je viens d'évoquer, des normes, la référence à celles-ci doit conduire en toute logique, à un moment ou à un autre, à demander le pouvoir de décision, ce qui pourrait constituer un mode de gouvernement des affaires publiques réellement alternatif au mode représentatif, et un challenge considérable. En principe, en effet, la démocratie participative conçue comme impliquant le pouvoir de décision pose un problème de cohérence logico-juridique avec la démocratie représentative; l'extension du champ de la démocratie participative signifie en effet en principe la réduction du champ de la démocratie représentative. Certaines des réactions actuelles - les gens se révoltent régulièrement contre le sentiment que la décision est de toute façon déjà prise au niveau gouvernemental avant même que le débat soit entamé - ne sont peut-être encore qu'une timide anticipation de ce que les individus les plus concernés devraient un jour, logiquement, explicitement demander, et qui semble parfois déjà percer: décider par eux-mêmes dans les matières qui les concernent directement $t^{15}$. Dans la mesure où les projets en question ont toujours des conséquences (avantageuses) pour d'autres personnes que les riverains, cela pose forcément problème à la fois du point de vue de l'intérêt privé de chacun et du point de vue de l'intérêt public.

Ces interprétations maximalistes - qui se répandent à la faveur d'ambiguïtés et de glissements terminologiques et restent pour l'instant souvent encore latentes portent pourtant plutôt la marque qu'on peut interpréter comme résiduelle d'utopies qui manquent assez manifestement de pertinence pour le temps présent, sauf exceptions étroitement circonscrites, même si l'on concède que rien ne se fait sans idéal, donc sans un brin d'utopie ${ }^{16}$. En ne rejetant pas clairement ces interpréta-

${ }^{14} \mathrm{C}$ 'est en cela que l'expérience de Porto Alegre diffère fondamentalement de l'expérience française, car, dans un certain nombre de contextes, les débats débouchent à Porto Alegre sur des décisions effectives (Gret et Sintomer [2005]). Qu'il s'agisse d'un point capital du débat est manifeste dans le fait que c'est l'une des raisons essentielles pour lesquelles cette expérience est présentée par les auteurs comme ayant valeur exemplaire.

${ }^{15}$ C'est aussi très explicitement dans ce sens-là que vont Gret et Sintomer (2002). Mais comme ils ne remettent cependant pas en cause radicalement la démocratie représentative traditionnelle, il subsiste en conséquence un grand flou, d'autant que les auteurs sont parfaitement conscients qu'à partir d'un certain nombre d'individus participant aux débats dans les quartiers, il faut des délégués les représentant au niveau municipal, et qu'à partir d'un certain degré de difficultés à traiter, ces délégués doivent pouvoir délibérer entre eux pour ajuster leur position, tenir compte de l'intérêt général, et décider sans revenir à chaque fois à la base: la démocratie représentative se trouve donc simplement réinventée et rencontre en conséquence sans surprise les problèmes mêmes que Sieyès avait déjà mis en évidence (pp. 124-129), ce dont les auteurs sont au demeurant parfaitement conscients (p. 125).

${ }^{16}$ On considère généralement que, en France, la loi Bourchardeau de 1983 a été le premier véritable acte engageant les gouvernements ultérieurs dans la direction de la démocratie de proximité. Or Huguette Bourchardeau, alors Ministre de l'environnement, avait aussi été secrétaire nationale du PSU. Le Manifeste du PSU (1972), porteur, comme chacun s'en souvient, de thèmes autogestionnaires, disait: «Il est indispensable que soient instaurés des niveaux de décision, capables d'entrer en conflit le cas échéant - avec l'Etat central, et plus proches de ceux qui sont directement concernés. En cas 
tions maximalistes, on risque de générer subrepticement de fausses attentes et donc des frustrations, porteuses de réactions futures contre la démocratie de proximité elle-même.

Symétriquement, ces interprétations empêchent paradoxalement de saisir la nature de la véritable innovation que présentent ces formes nouvelles de démocratie - innovation modeste mais réelle, notamment lorsque le débat est réellement organisé sous contrainte d'argumentation comme cela a été spécialement le cas de l'avis unanime des observateurs du débat de 1997-8 en Provence-Côte d'Azur que nous nous apprêtons à considérer plus en détail - et elles tendent en conséquence à accroître les problèmes que les innovations juridiques en question prétendent précisément, sinon tout à fait résoudre, du moins réduire: le manque d'《autorité» des pouvoirs publics (au sens de la légitimité de ces pouvoirs) et la faiblesse de la confiance qu'ils inspirent ${ }^{17}$. Elles tendent $a$ fortiori à détourner de la prise de conscience des virtualités des relations de confiance et d'autorité que porte précisément en elle l'instauration de débats publics argumentés en régime représentatif ainsi que des aménagements et améliorations qu'elle peut encore subir sous ces rapports dans un tel régime. Elles tendent enfin et plus fondamentalement à détourner des véritables problèmes que pose, dans un cadre rationaliste, la vie démocratique en tant que celle-ci semble irrémédiablement devoir se fonder sur des rapports de confiance et de respect de l'autorité que la pure raison devrait en principe proscrire.

Mon but, on l'aura compris, n'est nullement de faire le procès de la démocratie participative ou de la démocratie délibérative prises comme instauration de

de délégation de pouvoir, la révocation est ainsi effectivement possible: on se rapproche de la démocratie directe» (p. 111). Le Manifeste critiquait l'usage du référendum, "caricature de la démocratie», et prônait les «conseils de producteurs» (pp. 112-113), les conseils de quartiers, de résidents, de villages (pp. 113-114) et divers autres «collectifs» (pp. 114-116). Les motifs des ministres ultérieurs concernés (Bianco, Barnier, etc.) ont été, bien entendu, très différents.

Par ailleurs, si le marxisme de la Théorie critique de l'Ecole de Francfort d'où est issu Habermas n'a pas d'affinités particulières avec le courant socialiste autogestionnaire proprement dit, la philosophie d'Habermas comporte une théorie critique de la société sur laquelle continue de faire fond, tout en la modérant dans le sens d'un réformisme, l'idée de politique délibérative. Ainsi, dans la «Considération finale» de la Théorie de l'agir communicationnel, Habermas (1987) faisait l'inventaire des «potentialités de contestation» actuelles (T. II, pp. 431-437), lequel incluait les mouvements antinucléaires, écologiques, féministes, autonomistes, etc., et le plus englobant «mouvement alternatif» (p. 433), dont le mouvement altermondialiste est aujourd'hui clairement l'héritier (sur la filiation «soviets d'usines» (sic) - «assemblées de quartier» de type Porto Alegre, voir Gret et Sintomer, 2005, pp. 29-30). Si la philosophie politique d'Habermas est, de façon plus générale, une philosophie néorousseauiste ou néo-kantienne de l'autolégislation (cf. par exemple, Habermas [1998], pp. 282-284), Habermas a critiqué clairement dans ses écrits récents les limites de l'héritage spécifiquement anarchiste et marxiste de cette philosophie (les conseils ouvriers, les soviets), notamment la sous-estimation par cet héritage de ce qui est propre aux Lumières elles-mêmes, à savoir l'autolégislation par la raison (Habermas [1997], pp. 50-54). On peut constater une évolution comparable chez Joshua Cohen, un des penseurs centraux de la démocratie délibérative (cf. Bohman [1997a]): Cohen et Rogers (1983) se réclamaient, en effet, non seulement de Rousseau mais aussi de Marx (p. 11).

${ }^{17}$ Caractéristique de cette logique de l'accroissement du conflit, le passage précédemment cité du Manifeste du PSU: « des niveaux de décision, capables d'entrer en conflit - le cas échéant - avec l'Etat central $<$ je souligne $>$ ». Cette perspective résolument conflictualiste est bien sûr à comprendre dans le cadre de l'optimiste dialectique marxiste pour laquelle les interactions sociales sont essentiellement des «contradictions» et les contradictions toujours porteuses, à terme, d'effets dynamiques positifs. 
débats publics argumentés impliquant le pouvoir de décision - en tant qu'idéaux démocratiques. Ces idéaux pourraient bien, au contraire, constituer les idéaux démocratiques les plus élevés qui soient, au moins d'un point de vue rationaliste, dans la mesure où ils expriment seuls non seulement l'idée d'une autonomie politique («l'obéissance à la loi qu'on s'est prescrite ${ }^{18}$ ), qui est l'idéal traditionnellement qualifié de républicain (c'est aussi celui de la liberté positive au sens d'Isaiah Berlin [1979]), mais celle d'une autonomie atteinte par des moyens rationnels, c'est-à-dire obtenue non pas tant, comme chez Rousseau, par le seul «consensus des cœurs» que par «le consensus des arguments»-selon l'heureuse opposition de Jürgen Habermas ${ }^{19}$ - et se révéler, en outre, des idéaux pragmatiquement très pertinents dans un certain nombre de contextes variés mais très étroitement circonscrits ${ }^{20}$.

Aussi, au risque de paraître défendre un point de vue paradoxal au regard d'une opinion dominante en ces contextes, je me propose de formuler dans cet article un plaidoyer en faveur d'une interprétation minimale du sens de la démocratie de proximité (et qui ne paraîtra «minimaliste» qu'aux yeux d'adversaires réels ou potentiels de cette interprétation) et qui devrait éviter d'y voir des réalisations aussi bien de l'idéal de la démocratie participative que de la démocratie délibérative.

Je commencerai par me livrer à un exposé conceptuel élémentaire du sens classique des termes: «démocratie participative» et «démocratie délibérative» et des termes apparentés; ceux-ci, en effet, comme je l'ai déjà suggéré, peuvent avoir en des contextes différents un sens fort sensiblement distinct - notamment dans les usages récents de la littérature consacrée à la démocratie délibérative, puisque c'est celle-ci, plus que la démocratie participative, qui fait actuellement l'objet de nombreuses élaborations (Bohman [1997], Elster [1998]). Je comparerai à cette aune conceptuelle le sens possible des structures de démocraties de proximité (ou locales) récemment instaurées en France.

${ }^{18}$ Rousseau (1964 [1762]), Contrat Social, I, chap. 8.

19 Voir aussi l'article de Bernard Manin (1985), auquel renvoie lui-même Habermas (1992, p. XXV) et qui exprime cette belle philosophie (normative) de la démocratie délibérative: «la source de la légitimité n'est pas la volonté déjà déterminée des individus, mais son processus de formation, la délibération (...); c'est le processus de formation des volontés qui confère sa légitimité au résultat, non les volontés déjà formées». On ne confondra pas ce républicanisme raffiné mais classique avec une variante récente plus modérée, fondée sur la liberté conçue non plus comme autonomie (ou «domination sur soi-même») mais comme simple absence de domination d'autrui, récemment «inventée» par Pettit (2004), spécialement p. 247-252. Bohman (2006), ici même, renvoie également à cette conception de la liberté comme non domination. L'idée de politique délibérative qui se dégage de ce nouveau républicanisme $n$ 'implique pas plus que celle d'Habermas, en effet, le pouvoir de décision, et est donc hétérodoxe.

${ }^{20}$ Urfalino (2006), dans ce volume même, en donne un large et suggestif inventaire au-delà même du cadre des démocraties occidentales. Gret et Sintomer (2005) en donnent aussi des exemples convaincants, mais tendent à considérer paradoxalement (vu leur conscience des types de problèmes mis en évidence par Sieyès) comme presque résiduel le fait qu'il y ait des niveaux de débat dans l'expérience de la municipalité de Porto Alegre d'où le pouvoir de décision finit par être absent, exactement comme dans toute expérience de démocratie représentative. On notera que, vu cette similitude, les problèmes que je pose ici à propos de l'autorité et de la confiance se posent également dans le cas de l'expérience de Porto Alegre elle-même. 
En un second temps, dans une partie également conceptuelle, je me centrerai sur les notions communes d'autorité et de confiance - puisque ce sont ces relations qui requièrent, me semble-t-il, une attention réflexive particulière - pour les décomposer en quelques notions plus élémentaires et plus différenciées. Je m’y attacherai principalement à essayer de décrire de façon schématisée (ou «modélisée»), donc à un niveau général et abstrait, les processus de constitution - et symétriquement de dissolution - des relations tant d'autorité que de confiance aux nombreux niveaux où l'on est amené à les observer lorsque l'on considère dans le détail la séquence complexe que constituent les processus des décisions et d'application des décisions dans un Etat moderne.

Dans la dernière partie, libéré des interprétations maximalistes (et virtuellement radicales) de la démocratie locale mais armé des modèles conceptuels élémentaires de l'autorité et de la confiance, je me livrerai à une description détaillée de la dynamique ${ }^{21}$ des relations de confiance et d'autorité entre l'Etat et les citoyens à l'œuvre dans un débat de type loi Barnier effectif, celui qui s'est tenu en Provence-Côte d'Azur en 1997-8 sur un projet d'installation d'une ligne électrique à très haute tension, débat qui, comme je l'ai mentionné, apparaît à tous les analystes comme paradigmatique de ce que peut être une bonne application de la loi Barnier de 1995. Cette analyse empirique constituera évidemment la pierre de touche de la pertinence à la fois de l'axe général d'analyse ici choisi et des analyses conceptuelles particulières proposées.

\section{CRITIQUE DES INTERPRÉTATIONS MAXIMALISTES DE LA DÉMOCRATIE DE PROXIMITÉ EN TERMES DE DÉMOCRATIE PARTICIPATIVE ET DÉLIBÉRATIVE}

\section{Introduction}

Mon propos est ici de revenir avec quelques détails, quoique dans les limites du nécessaire, sur les notions de démocratie participative et de démocratie délibérative en mettant en évidence - sans prétention à l'exhaustivité - certaines ambiguités et flottements de sens, porteurs d'illusions sur certaines réformes récentes mettant en place une certaine démocratie de proximité ${ }^{22}$. Je procéderai en prenant successivement les notions de démocratie participative et de démocratie délibérative et les concepts élémentaires qui leur sont associés: participation et délibération, en prenant garde aux usages linguistiques parfois assez différenciés des termes qui renvoient à ces concepts et les véhiculent.

\section{A. Deux concepts de participation}

On peut distinguer aisément un usage large et un usage étroit des termes «participation» et «participatif», renvoyant à deux concepts, dont l'un est le concept

${ }^{21}$ On pourrait même dire en certaines occasion: «la dialectique», vu les mouvements d'interaction réciproques constatés.

22 Je laisse de côté la question psychologique de savoir si - ou dans quelle mesure - ces ambiguïtés causent l'illusion ou si elles la facilitent seulement, comme celle de savoir dans quelle mesure ces ambiguïtés seraient réciproquement un effet de cette illusion. 
d'un processus pris en son ensemble (et parfois sans contours précis) et l'autre le concept d'un moment très circonscrit du même processus. Je commencerai par exposer le sens de ce dernier concept.

a) «Participation» et «participatif» au sens restreint.

Une pratique typique de la démocratie participative (stricto sensu):

le référendum.

On oppose conceptuellement très communément depuis quelques temps démocratie représentative et démocratie participative comme deux modes de prise de décision différents des lois et règlements divers ${ }^{23}$. En parlant de la démocratie participative par opposition à la démocratie représentative, on semble donc signifier en fait, de façon elliptique, participation directe, c'est-à-dire participation directe à la décision des lois ou des règlements (par un vote, par exemple) auxquels le citoyen (et plus généralement les résidents d'un pays) devront ensuite obéiir ${ }^{24}$.

Conformément à cet usage fort répandu, lorsqu'on dit que la plupart des démocraties contemporaines sont des démocraties authentiquement hybrides, on semble vouloir dire en général que les démocraties contemporaines juxtaposent, en des proportions variées, des procédures de participation indirecte à la prise de décision politique - notamment à travers l'élection des représentants (membres du Parlement, membres du Congrès, délégués divers, etc.), qui seuls participeront directement aux décisions par le vote des lois - et des procédures de participation directe à la prise de décision - i.e. permettant des décisions prises par les citoyens ou les résidents eux-mêmes. Par procédure directe, on pense le plus souvent à la pratique référendaire, qui est le mode contemporain le plus fréquent de la prise de décision directe concernant les lois lorsque le nombre des votants est important. Les débats publics de type loi Barnier ne sont donc en rien des illustrations de la démocratie participative au sens étroit habituel de cette expression, puisqu'il leur manque le trait définitoire même de celle-ci: le pouvoir de décider.

\section{b) «Participation» au sens englobant.}

Lorsqu'on décrit les formes nouvelles de démocratie de proximité comme des expériences de démocratie «plus participative» ${ }^{25}$, on veut évidemment dire autre chose puisque presque jamais l'ensemble de ceux qui participent aux débats en question ne décident ${ }^{26}$. On parle certes parfois d'une participation au processus de décision, mais c'est que l'on pense alors au processus de décision dans son ensemble; or celui-ci inclut non seulement le moment de la décision proprement dit ni non plus seulement celui-ci précédé du moment de la délibération, celui où

${ }^{23}$ La notion de «démocratie participative» est récente; on ne la trouve dans aucun des index des quatre tomes du Traité de science politique ss la dir. de M. Grawitz et J. Leca (1985); on trouve certes l'entrée «démocratie de participation» (index thématique du tome II), mais ce n'est pas la même chose, et l'entrée «démocratie et participation» (index thématique du tome III), mais il s'agit encore d'autre chose.

${ }^{24}$ C'est manifeste par exemple dans Gret et Sintomer (2002): les auteurs utilisent «démocratie participative» et «démocratie directe» de façon à peu près interchangeable.

${ }^{25}$ Voir Blatrix [1997], pour des exemples de tels usages.

${ }^{26}$ L'expérience de Porto Alegre étant précisément sur ce point, encore une fois, l'exception. 
l'on pèse le poids respectif des arguments (voir infra), mais la phase même de formation et de collecte des positions et des arguments en présence, phase qui précède le moment délibératif lui-même. Car ceux qui décident, dans le cas de ce qui est en jeu dans les débats publics loi Barnier, ce sont, au niveau de la mise en place du projet, le ou les ministres, et, aux degrés inférieurs d'exécution du projet, le maître d'œuvre de l'ouvrage projeté ${ }^{27}$ (le maître d'œuvre est ainsi le seul parmi ceux qui participent au débat à avoir un certain pouvoir de décision concernant le projet débattu, encore que seulement dans les détails de l'exécution), les uns et les autres tenant compte, dans les cas favorables, du contenu des débats menés par les participants au débat organisé. Mais ces débats eux-mêmes ne font partie que de la phase préalable à la délibération proprement dite.

En raison de la synonymie fréquente établie entre les expressions de «démocratie participative» et de «démocratie directe» et l'opposition de la démocratie participative à la démocratie représentative qui s'en infère, dire qu'il faut davantage de démocratie participative n'a pas exactement les mêmes effets rhétoriques que dire qu'il faut davantage de participation à la vie démocratique ${ }^{28}$. Il est clair, en effet, que dans toute forme de démocratie représentative, il y a de toutes façons une part de participation (ne serait-ce qu'au travers de l'élection des représentants du peuple et des gouvernants, lesquels auront le pouvoir de décider des lois ou de les appliquer) - mais il ne s'agit pas d'une participation à la décision même des lois. En ce sens très englobant du terme «participation», il y aurait même sens à s'indigner de ce que les représentants du peuple eux-mêmes ne participent pas assez aux débats du Parlement, voire qu'ils ne participent pas à la vie parlementaire plus globalement encore, par exemple en s'absentant régulièrement de prendre part aux votes (lorsque les enjeux ne leur semblent pas importants ou que les votes sont des votes passifs de partis, effectuables par délégation). Mais, au risque de se répéter, on doit faire remarquer que, sauf à confondre les concepts -

${ }^{27}$ Dans le cas empirique qui nous intéressera de près tout à l'heure, le maître d'œuvre est EDF et l'ouvrage projeté une ligne à THT.

${ }^{28}$ Le sens du principe de participation lui-même varie considérablement. Ainsi, John Rawls (1991), parag. 36 et 37 (p. 257-271, spécialement p. 264) écrit: «Le principe de participation [...] ne définit pas un idéal du citoyen ni un devoir exigeant que tous participent activement aux affaires politiques» (p. 264). En effet, il concerne non pas le citoyen mais la forme des institutions elles-mêmes; c'est donc plutôt pour le législateur qu'il s'agit d'une norme. Par ailleurs, Rawls considère que l'application du principe commence dès le niveau très élémentaire du droit de vote égal pour tous. Rawls semble surtout préoccupé de dire qu'il n'y a pas nécessairement à donner au principe de participation le sens plein et radical qu'il a dans ce qu'on appelle parfois la tradition de la «participatory democracy» (notamment Pateman [1970]), laquelle insiste moins elle-même sur le droit de vote ou sur le droit de participer à la vie politique en général que sur le fait que la participation (au sens large ou englobant) des citoyens a une vertu pédagogique: le but de la participation n'est pas simplement l'expression de la liberté de chacun mais plus fondamentalement «la transformation et l'éducation des participants» (cf. Elster [1986], p. 103; cf. aussi Memmi [1985], pp. 351-354). L'interprétation que Rawls donne du principe de participation fait qu'on peut dire que celui-ci commence déjà à être appliqué dans une conception simplement libérale (Locke, Constant, Tocqueville). En revanche, l'idée que la participation (définie globalement) à la vie politique a une vertu intrinsèque (pédagogique ou non) ne se rencontre que dans la tradition républicaine (cf. Pettit [2004]); ce peut même être la virtus par excellence de la démocratie. Le sens radical (Pateman [1970]) semble parfois latent dans les revendications françaises de davantage de participation à la vie politique; mais il ne l'est pas toujours, le concept étant le plus souvent utilisé de manière beaucoup plus indéterminée sans référence à une théorie élaborée. 
ce qui, en ces matières, est fréquent -, l'existence de ce genre de participation ne fait pas encore, à quelque degré que ce soit, une démocratie participative, si l'on considère que le pouvoir des citoyens de décider lui est inhérent.

En ce sens large (et assez indéterminé) du terme «participation», qui ne requiert pas le pouvoir de décider, on peut incontestablement dire que la loi Barnier (sous sa forme amendée en 2002) et la loi sur la démocratie de proximité étendent la participation des citoyens, puisque ceux-ci peuvent donner leur avis et que le pouvoir consultatif leur est même reconnu ${ }^{29}$. Mais on voit qu'il convient de distinguer les pratiques référendaires, qui sont authentiquement participatives au sens restreint (quels que soient les reproches que l'on peut faire, par ailleurs, à la qualité de cette participation $)^{30}$, puisque les citoyens décident eux-mêmes des lois auxquelles ils devront ensuite obéir, d'autres pratiques qui n'en relèvent pas (quelle que soit la qualité que l'on peut, par ailleurs, leur reconnaître) ${ }^{31}$, mais qui relèvent, en revanche, de l'introduction de débats organisés au sein de la population, par exemple concernant des décisions d'aménagement susceptibles d'avoir des incidences particulières sur les riverains et que visent notamment à encadrer les lois sur ce qu'on appelle en France la démocratie de proximité.

Lorsqu'on parle de «démocratie participative» à propos des débats publics du type loi Barnier, on facilite ou on entretient donc la confusion avec un type de pratique dont le principe est tout à fait différent (et on verra à quel point, plus encore, bientôt). Cette confusion est parfois entretenue avec une innocence un peu confondante lorsque le terme même de «référendum» est utilisé pour désigner des formes de démocratie de ce genre, comme les conseils de quartier (qui n'ont pas non plus pouvoir décisionnel), au nom d'une «commodité de langage», alors même que l'on est parfaitement conscient de la différence tranchée entre les deux institutions (Blatrix [1997], p. 233, n.1) ${ }^{32}$. L'usage est moins innocent lorsque la même expression est utilisée dans les mêmes cas par des hommes politiques connus par ailleurs pour demander l'extension de l'usage du référendum plus que celui des débats publics argumentés ${ }^{33}$.

${ }^{29}$ L'exigence de Bohman (2006) que les citoyens aient la capacité à influer sur l'agenda des questions à traiter (une expression de leur «capacité d'initiative») est jusqu'à un certain point satisfaite puisque la loi de 2002 a ainsi étendu ce qu'on appelle le pouvoir de saisine.

${ }^{30}$ Du point de vue de la tradition radicale de la participatory democracy, le référendum est encore une bien piètre manière de participer.

${ }^{31}$ Les participants peuvent ici, à l'inverse, être remarquablement informés et avoir pu débusquer les biais idéologiques divers des démagogues.

${ }^{32}$ L'usage du terme «référendum local» en pareille occasion est, au demeurant, très répandu (cf. Puyfaucher [sans date]).

${ }^{33}$ Cf. par exemple le sénateur et ancien ministre Charles Pasqua, cité par Blatrix (1997). En principe le référendum devrait avoir une valeur supérieure aux consultations, même fondées sur le débat, du point de vue de la liberté-autonomie, dans la mesure où il dote le peuple du pouvoir de décider. Mais l'organisation d'un référendum ne garantit pas qu'il y ait une qualité de la discussion préalable ni même qu'il y ait du tout discussion, de sorte qu'il ouvre la porte aux manipulations oratoires (d'où les soupçons de populisme et de démagogie à l'égard de ceux qui prônent l'extension de l'usage des référendums sans imposer de strictes conditions à sa mise en pratique), auxquelles seraient moins sensibles, par formation, des représentants du peuple. En outre, en demandant une réponse par oui ou non, le référendum ferme la porte à la transformation ou à l'amendement éventuel du projet grâce à l'échange d'arguments. Voir, à nouveau, sur ces questions, Manin (1985). 


\section{B. Deux critères pour l'usage du concept de délibération}

Le concept de délibération varie lui aussi de contenu selon les contextes et davantage encore que le concept de participation. Il est commode de distinguer deux critères d'usage, que l'on pourrait retrouver dans les usages les plus classiques mêmes du terme, i.e. aristotéliciens (ou ayant un fort air de famille avec certains des usages aristotéliciens les plus fameux): selon que la délibération est conçue comme intrinsèquement liée à une décision (sens aristotélicien ${ }^{34}$ ) ou qu'elle ne l'est pas; selon que la délibération est conçue comme visant nécessairement le bien public (sens aristotélicien ${ }^{35}$ ) ou non. Je vais examiner ces différents sens en considérant successivement les deux critères; selon que celui-ci est ou non rempli, on pourra en conséquence à chaque fois distinguer deux sens.

a) Délibération comme débat argumenté menant à une décision de la part des débattants (= sens englobant et classique) versus délibération comme simple débat argumenté $(=$ sens restreint et même tronqué et donc laxiste par rapport au sens précédent)

La notion de démocratie délibérative n'existe pas plus dans le langage juridico-politique classique que la notion de démocratie participative. C'est également une notion nouvelle et même d'usage un peu moins répandu. Je partirai ici des usages du concept de délibération, en partant du sens classique le plus usuel.

Au sens classique (aristotélicien), on délibère toujours en vue d'une décision. Délibérer, au sens classique, c'est peser le pour ou le contre entre plusieurs alternatives et, au terme de ce balancement, décider ${ }^{36}$. Le lieu typique de la délibération est une assemblée politique (les Grecs, toujours à l'arrière-plan des débats sur la nature de la démocratie, appelaient «boulè» l'assemblée délibérante) ${ }^{37}$ où tous les citoyens qui le veulent s'expriment, chacun avançant des arguments «pour» ou «contre» une décision (typiquement, le vote d'une loi) en discussion. L'échange des

${ }^{34}$ Dans un des passages les plus célèbres et qui a eu le plus d'influence sur toute la philosophie (et la théorie) de l'action occidentale de l'Ethique à Nicomaque, Aristote a analysé le choix dit préférentiel (proairesis), i.e. celui qui a lieu lorsqu'on préfère une chose à une autre et qui est précédé d'une délibération. Aristote prolonge alors par une analyse de la délibération (bouleusis) et écrit ainsi: «Nous délibérons sur les choses qui dépendent de nous et que nous pouvons réaliser» (III, 5, 1112a, 31), ce qui exclut que l'on parle de délibération pour ce qui ne relève pas de notre décision. Manin (1985, p. 80) cite un texte de la Rhétorique qui va dans le même sens.

${ }^{35}$ Dans un passage non moins célèbre et non moins influent, Aristote écrit encore: «Nous délibérons non pas sur les fins elles-mêmes mais sur les moyens d'atteindre les fins: (...) un politique [ne se demande pas] s'il établira de bonnes lois» (III, 5, 1112b 12), mais seulement comment il fera de bonnes lois. Aristote dit donc implicitement qu'un législateur vise en principe le bien public (que, dans les faits, cela n'aille évidemment pas de soi n'a aucune d'importance quant à la détermination du contenu conceptuel de la notion).

${ }^{36}$ Je rejoins ici Manin (1985, p. 78): «La tradition philosophique suivant un usage qui remonte à l'aristotélisme, désigne en général, par le terme de délibération, le processus de formation de la volonté, ce moment qui précède le choix (...)». Conformément à cet usage classique, Rawls (1987) lie également de façon intrinsèque délibération et décision (cf. parag. 64, pp. 457-473, «La délibération rationnelle»). Manin (1985, pp. 80-81) montre même que Rawls tend à réduire la délibération à la décision (cf. infra).

${ }^{37}$ C'est de «boulè» que vient «bouleusis» (délibération) lui-même. 
arguments constitue la délibération publique; celle-ci doit éclairer le jugement de chacun $^{38}$. Au terme de cette «mise en balance» des arguments, chacun est à même de juger et de voter en conséquence. On peut même ajouter que, si le jugement de chacun était toujours éclairé et l'estimation du poids respectif des arguments aisée, chacun se rangerait au meilleur argument en abandonnant éventuellement en conséquence sa position initiale; le consensus serait alors la règle et le vote inutile $\mathrm{e}^{39}$.

Il n'y a donc pas de sens (si l'on suit les usages classiques influents jusqu'à nos jours) à découpler la délibération du processus de décision au sens où ceux qui délibéreraient ne seraient pas également ceux qui prennent les décisions. Si les membres d'une assemblée échangent des arguments mais n'ont pas pouvoir de décider, on ne peut pas dire qu'ils ont délibéré. D'un autre côté, si les arguments qui ont été échangés sont portés à la connaissance de ceux qui ont pouvoir de décider - ce qui n'était même pas le cas des débats instaurés par la loi Barnier avant les modification de 2002 -, on peut simplement dire que ces arguments nourriront, s'il en est tenu compte, la délibération des décideurs ${ }^{40}$. Mais ce sont ces derniers et eux seuls qui délibéreront: les ministres en Conseil des ministres ou en conseil restreint, voire éventuellement le ministre de l'Environnement en son for intérieur ${ }^{41}$.

${ }^{38}$ Les débats d'une telle assemblée, par exemple entre les représentants du peuple au sein des parlements modernes, sont publics au sens où les raisons des décisions à prendre sont exprimées publiquement entre ceux qui délibèrent; mais ils peuvent être publics en un sens plus large, par exemple au sens où tout citoyen qui le souhaite et qui en a le temps et les moyens (en termes de déplacement) peut y assister (les débats parlementaires sont même parfois désormais retransmis sur certaines chaînes spécialisées). Mais le fait de profiter de la publicité des débats, et même celui de participer au débat, ne constituent pas encore une participation à la décision (typiquement, en votant). Pour des sens encore plus étroits du terme «public», mais que je n'ai pas à considérer ici, voir encore Rawls (1995), pp. 259260.

${ }^{39}$ De là vient que certains auteurs, par un processus de typification, opposent radicalement délibération et vote (Pasquino [2006], et Urfalino, 2006 [dans ce volume]).

${ }^{40}$ De ce point de vue, il est donc erroné (et éventuellement trompeur) de dire, comme il est fréquent en ce contexte, que les débats publics relèvent de la «phase délibérative». Celle-ci ne commence à strictement parler, comme on l'a vu, que lorsque les ministres mettent sur le tapis la question de savoir si oui ou non le projet sera mis en place. C'est cette erreur conceptuelle (erreur du point de vue du concept étroit) qui conduit à voir de la démocratie délibérative dans les débats publics de proximité type loi Barnier. Les formulations des textes juridiques sont, en revanche, très claires; ainsi, à propos d'un autre exemple de démocratie de proximité déjà évoqué et désigné faussement comme «référendum communal», le Code des communes prévoit que «les électeurs de la commune peuvent être consultés sur les décisions que les autorités municipales sont appelées à prendre pour régler les affaires de la compétence de la commune» (art. L.125-1). Mais qui délibère dans ce cadre? Le conseil munici$\mathrm{pal}$ - et à deux reprises - et lui seulement: une première fois «le conseil municipal délibère sur le principe et les modalités d'organisation de la consultation» (art. L.125-2); une seconde fois, après la consultation des électeurs: «Après avoir pris connaissance du résultat de la consultation, le conseil municipal délibère dans les conditions prévues à l'article L.121-12» (articles cités par Blatrix [1997], p. 235). On remarquera ici non seulement que la délibération précède une décision mais que l'idée de décider est comprise dans l'idée même de délibération puisqu'il n'est pas précisé: «délibère puis décide», alors qu'il s'agit bien de dire que le conseil décide.

${ }^{41}$ Dans une Cour de justice, on distingue clairement ceux qui apportent des informations (témoins, experts), ceux qui argumentent sans décider (avocats, procureur) et ceux qui délibèrent - en argumentant bien entendu eux-mêmes (le ou les juges ou le jury) devant les autres ou pour eux-mêmes - pour décider. 
Si la notion de démocratie délibérative n'est pas une notion encore établie dans les usages juridico-politiques, il est usuel en droit contemporain, en revanche, d'opposer les assemblées consultatives aux assemblées délibérantes (en anglais: deliberative) et le pouvoir (simplement) consultatif au pouvoir délibératif, de même que la voix consultative à la voix délibérative. Or, en ce contexte, le pouvoir délibératif veut toujours dire: le pouvoir de décider, en général par un vote ${ }^{42}$. Comme on vient de le voir, la loi Barnier ne reconnaissait pas même aux assemblées constituées lors des débats un pouvoir consultatif. Le Président de la Commission devait simplement attester que le débat avait bien eu lieu sans avoir à émettre d'avis. Et si la loi de 2002 accorde ce pouvoir consultatif, elle n'accorde évidemment pas le pouvoir délibératif (le pouvoir de décider). Au sens classique le plus établi, les débats de type loi Barnier ou loi 2002 ne sont donc pas du tout des débats délibératifs et donc pas du tout des exemples de démocratie délibérative $e^{43}$. En revanche, les débats au Parlement sont typiquement délibératifs puisque le Parlement a le pouvoir de voter des lois ${ }^{44}$. Encore faut-il que ces débats existent. Tout un courant de la politique américaine des années 1970 s'est alarmé du manque de débats (ou de délibérations) au Congrès, les membres du Congrès votant sans avoir réellement discuté entre eux mais obéissant plutôt à une simple logique de parti, alors que les débats pourraient modifier les positions (les «préférences»). De façon conséquente, nombre d'auteurs

${ }^{42}$ L'expression est de facto galvaudée puisque des membres d'une assemblée qui voteraient sans avoir du tout pesé le pour ou le contre dans un débat préalable entre eux (donc délibéré stricto sensu) seraient quand même dits, juridiquement parlant, exercer leur «pouvoir délibératif». Paradoxalement donc, si l'idée d'estimation comparée des arguments se perd ici, l'idée de décision, elle, subsiste. En ce cas, le pouvoir délibératif, c'est davantage le pouvoir même de décider que celui de peser le pour ou le contre entre différentes options. La notion de délibération se déplace donc ici sur le pôle opposé à celui que je stigmatise ici, mais d'une façon tout aussi illégitime. Manin (1985, pp. 78-79) note de façon éclatante que telle est aussi la conception de la délibération chez Rousseau, de sorte qu'il n'y a aucune place pour l'argumentation (même avec soi-même) dans la construction rousseauiste de la volonté générale. Manin (pp. 80-81) ajoute très justement qu'il y a une filiation entre Rousseau et le Rawls de la Théorie de la justice sur ce point.

${ }^{43}$ Nombre de théoriciens de la démocratie délibérative considèrent ce critère (le pouvoir décisionnel) comme étant absolument nécessaire (Elster [1986], notamment; Pasquino, 2006, dans ce volume), de sorte que parler de démocratie délibérative à propos des débats de proximité de type loi Barnier est manifestement de leur point de vue une erreur de catégorie caractérisée (c'est confondre deux choses qui n'ont rien à voir entre elles puisqu'il manque précisément à l'une d'entre elles le trait nécessaire et donc définitionnel). Mais des expériences comme celle de la municipalité de Porto Alegre montrent que les formes concrètes de démocratie peuvent évoluer très vite d'un type à un autre: pendant un temps, les assemblées de quartier sont seules délibérantes (elles discutent et elles votent), les délégués à l'échelon supérieur n'étant que des porte-parole; le nombre des participants croissant et les affaires se complexifiant, les assemblées de quartier continuent de discuter mais perdent le pouvoir de décider, lequel revient aux délégués qui à la fois discutent et décident.

${ }^{44}$ Toutefois ils ne le sont pas si l'on utilise le critère encore plus exigeant de Pasquino. Pasquino (2006) stylise (ou «typifie») en effet le concept de délibération au point de n'appeler délibératif non seulement qu'un débat argumenté débouchant sur une décision mais encore selon un mode de décision obtenu exclusivement par convergence des arguments (donc unanimité) et sans avoir du tout recours au vote (sauf éventuellement pour enregistrer formellement le résultat déjà acquis de la délibération). Voir aussi Elster (1986) et Urfalino (2006). A l'époque moderne, les exemples de démocratie délibérative en ce sens très stylisé sont extrêmement rares. Pasquino donne l'exemple des Cours constitutionnelles. Pour Elster, les débats habituels au Parlement ne sont pas non plus une délibération, mais pour un autre motif. Sa stylisation est aussi exigeante mais procède d'un autre critère (cf. infra). 
qui soit se réclament de la démocratie délibérative au plan normatif, soit utilisent le concept au plan descriptif, prennent l'expression en ce sens-là et parlent donc essentiellement de démocratie délibérative dans le contexte de la démocratie représentative, par exemple pour parler des débats constitutionnels ${ }^{45}$.

Mais néanmoins, on voit de plus en plus utiliser le terme de démocratie délibérative pour désigner des débats argumentés qui ne débouchent pas nécessairement sur une décision de la part de ceux qui débattent ${ }^{46}$. C'est en ce sens que nombre d'auteurs post-habermassiens comme James Bohman ou Joshua Cohen parlent de démocratie délibérative ou de politique délibérative ${ }^{47}$. C'est en ce sens aussi, tronqué par rapport au sens précédent classique, que l'on entend parfois parler de démocratie délibérative à propos des débats publics type Barnier ou des associations de quartier à la française (par opposition à la pratique brésilienne de Porto Alegre).

b) Délibération comme débat argumenté visant le bien public (ou des valeurs) (= sens étroit) versus délibération comme débat argumenté ne visant pas nécessairement le bien public (= sens large).

Dans le contexte des débats sur la démocratie délibérative, on donne toutefois encore souvent un autre sens au terme «délibération» et qui consiste en une spécification des deux sens précédents selon un autre critère. Je l'indique, d'une part pour la clarté de mon propos, d'autre part parce qu'il est utilisable dans le cadre de l'analyse du débat que je considère essentiellement; néanmoins, ce sur quoi je porterai mon attention dans la suite de cet article (les relations d'autorité et de confiance impliquées dans les processus de décision collectifs) n'est pas spécifiquement concerné par cette dimension. Selon ce critère, sont délibératifs au sens étroit, parmi les débats argumentés, ceux-là seuls qui visent le bien public par opposition à ceux qui visent la satisfaction des intérêts particuliers et relèvent donc du marchandage ou de la négociation, que ces débats s'achèvent ou non par une décision de la part des débattants ${ }^{48}$.

${ }^{45}$ C'est le cas, par exemple, d'Elster (au plan descriptif: Elster [1998b et 2006], dans ce volume). Toutefois, comme je l'ai dit, Elster utilise un idéal-type encore plus exigeant (infra).

${ }^{46}$ C'est, à mon sens, la raison profonde de l'étonnement dont témoigne Bernard Manin (2002, p. 42) de ce que son article de 1985 ait eu un écho (tardif) en France dans cette tradition récente spécifique. Manin n'identifiait pas encore en 1985 (p. 78, n. 20) ce sens du terme «délibération», qui n'est ni aristotélicien ni (a fortiori) rousseauiste. Comme on l'a vu, c'est aussi désormais un des sens de deliberative en anglais (Gastil, J. et P. Levine [eds], 2005).

47 J. Cohen (1997), par exemple, dit explicitement que la démocratie directe n'est pas le seul moyen d'institutionnaliser la démocratie délibérative, mais il est clair qu'il ne dit pas non plus qu'il ne peut y avoir délibération qu'entre représentants du peuple (p. 84). Pour Cohen, il y a délibération (au sens de la simple discussion argumentée) sur des «arènes» appropriées (p. 85), dont la nature reste fort indéterminée. Cf. aussi Bohman et Regh (1997), pp. IX-X.

${ }^{48}$ Rawls (1995), dans la leçon VI de Libéralisme politique consacrée à «La raison publique», leçon reprise par Bohman (1997) ne s'intéresse qu'aux débats concernant les questions constitutionnelles essentielles et les questions de justice fondamentales (pp. 260-261) et aux autres débats (y compris ceux qui concernent les «décrets protégeant l'environnement et contrôlant la pollution, établissant les parcs régionaux et protégeant les réserves naturelles», p. 261) qu'en tant qu'ils impliquent ces problèmes fondamentaux, ce qui n'est pas le cas le plus fréquent (pp. 261-262). C'est donc plutôt le matériau étudié par Pasquino (2006) dans ce volume qui serait ici pertinent pour analyser au plan empirique effectif les questions proprement rawlsiennes. 
Sans vouloir tomber dans un inventaire gratuit - un certain nombre de ces modèles nous serviront dans la partie proprement empirique pour penser des micro-séquences du débat public - il faut ainsi remarquer que chez Elster, les deux critères doivent être remplis ( 1 / les débattants décideront eux-mêmes 2 / au terme d'un débat au cours duquel ils ont visé - au moins apparemment - le bien public). C'est donc à bon droit ici, en effet, que Marion Gret et Yves Sintomer renvoient à Elster lorsqu'ils qualifient l'expérience participative de la municipalité de Porto Alegre comme «délibérative» car les critères de décision et de visée du bien public sont bien l'un et l'autre présents au moins tant que le phénomène n'a pas pris trop d'ampleur (cf. supra) ${ }^{49}$.

On rencontre des variantes de ce critère dans la littérature sur la question, dont on peut vérifier qu'elles ont elles-mêmes une pertinence empirique. Ainsi une idée répandue, présente notamment chez Elster et chez Habermas, est que le seul fait d'avoir à délibérer, donc à présenter des arguments en faveur d'une option ou contre une autre option, contraint de facto à se détacher de ses propres intérêts et à parler au nom des valeurs. Mais pour Habermas, cela exige qu'on se réfère à la norme de la bonne argumentation ou à l'éthique de la discussion (qui exige forcément honnêteté, sincérité, etc.). Elster fait implicitement valoir, au contraire, qu'une telle éthique n'est pas même nécessaire car la seule hypocrite apparence de recherche du bien public a, à elle seule, une valeur "civilisatrice», comme Vauvenargues et Kant l'avaient montré: il apparaît en général indécent aux acteurs de trop faire valoir leurs intérêts personnels lorsque les enjeux les dépassent à l'évidence, et le cours du débat en est donc changé. Dans des interprétations encore plus optimistes, la discussion argumentée apparaît même capable de modifier les préférences - mais plus souvent seulement les préférences affichées? - des individus (dont on sait bien que le plus souvent ils ne visent pas le bien public), quand bien même cette discussion ne débouche pas sur une décision. Il y a donc une valeur en quelque sorte quasi éthique (sinon véritablement éthique) de la simple procédure argumentative elle-même. Et on peut observer effectivement que dans le type de débat public que nous considérons ici, comme en général dans les débats du même type - d'après tous les observateurs -, les participants n'usent en général guère d'arguments de type NYMBY (Not In My Backyard).

Les débats publics de type loi Barnier tombent sous ce second critère - et dans sa variante elstérienne, i. e. au sens où argumenter suffit souvent à orienter vers le bien public ${ }^{50}$. Toutefois, lorsqu'il y a une contrainte d'argumentation forte, comme cela a été le cas de l'avis général des observateurs dans l'exemple du débat en PACA en 1997-8 (notamment en raison de la façon dont le Président de la Commission a exercé sa fonction $)^{51}$, on est dans une situation très proche de la situation habermassienne, la procédure extérieure pressant de suivre certaines des règles d'une bonne argumentation, comme le souci de cohérence logique, le souci

${ }^{49}$ Les auteurs font en effet référence (p. 116) à un article d'Elster (1994) pour une distinction qui reprend les distinctions élaborées par Elster (1986), dans son fameux article, entre argumenter ou délibérer (en vue du bien public) et négocier (sur des intérêts particuliers), le vote étant lui-même considéré comme un troisième mode de décision.

${ }^{50}$ Mais ces débats, comme on l'a vu, ne satisfont toutefois pas le premier critère esltérien: avoir le pouvoir de décision.

${ }^{51}$ Cf. Puyfaucher, sans date, p. 2 
de validation empirique, le respect des arguments d'autrui, la sincérité, etc. On pourrait même dire plus précisément que l'innovation principale de ces débats réside dans l'instauration d'une procédure juridique originale, une instance (en l'occurrence la Commission particulière du débat public) ${ }^{52}$, dont l'une des deux fonctions essentielles est d'organiser les débats de façon à ce que les règles d'une bonne argumentation soient respectées par les participants ${ }^{53}$.

Je conclurai ce moment de mon analyse en disant qu'il ne suffit donc pas que le principe de participation soit introduit dans les institutions d'une démocratie pour qu'on puisse parler de démocratie participative au sens qu'a cette expression quand on l'oppose, comme c'est le plus souvent le cas actuellement en France, à la démocratie représentative, et qu'il ne suffit pas non plus que le principe de discussion argumentée soit introduit dans les institutions d'une démocratie pour qu'on puisse parler de démocratie délibérative au sens où l'on parle communément en droit d'assemblée délibérative ou délibérante et qui implique que les délibérants aient le pouvoir de décision ${ }^{54}$. La démocratie délibérative prise au sens classique et juridique de «délibératif» relèverait plutôt de ce que l'on pourrait appeler un principe de décision venant s'ajouter aux deux principes précédents. Mais, en revanche, les débats publics instaurés par la démocratie dite de proximité peuvent être considérés comme des mises en œuvre de l'un et l'autre des deux premiers principes, le principe de participation (au sens rawlsien) et le principe de discussion argumentée sans mise en œuvre du troisième principe, le principe de décision, lequel seul justifie, à mon sens, que l'on parle de démocratie délibérative sans galvauder ce que les philosophes classiques comme les juristes contemporains appellent spécifiquement «délibération» ${ }^{55}$.

\section{UNE MODÉLISATION CONCEPTUELLE ÉLÉMENTAIRE DES RELATIONS D'AUTORITÉ ET DE CONFIANCE}

La démocratie de proximité resituée longuement - mais, j'espère, grâce à cet excursus terminologique et conceptuel, précisément - dans le cadre «minimal» qui me semble devoir être le sien, il convient maintenant de reprendre la question

${ }^{52}$ Cette Commission particulière est nommée par la Commission nationale du débat public. Il y a autant de Commissions particulières qu'il y a de débats publics instaurés sur un problème particulier (ceux-ci se sont multipliés ces dernières années).

${ }^{53}$ Une autre fonction est d'empêcher que les revendications des participants sortent du cadre des lois établies.

${ }^{54}$ Habermas, dans sa préface à la réédition en 1990 de sa thèse sur L'espace public (initialement parue en 1962) semble, au contraire, encore identifier la démocratie délibérative à une simple «conception discursive de la démocratie» (p. XXV). Mais le fondement de l'idée habermassienne de politique délibérative était bien seulement dans une «éthique de la discussion», dont le noyau est constitué par un «Principe de Discussion» (dit «principe D»). Cf. Habermas (1986), notamment pp. 87 et 114-115. Avant Droit et Démocratie, il y a régulièrement glissement chez Habermas de l'idée de discussion (argumentée) à celle de délibération et réciproquement. On ajoutera que lorsque Habermas parle de participation, il ne s'agit que de participation à la discussion, non à la décision (cf. l'énoncé du principe de discussion en introduction de ce volume).

${ }^{55}$ Le Handbook of Deliberative Democracy de J. Gastil et P. Levine (2005) est donc plutôt, à mon sens, un Manuel de démocratie participative et débattante. 
à laquelle cette innovation juridique est censée répondre et qui est, grosso modo, la question du déficit en autorité des pouvoirs publics puisque ceux-ci échouent régulièrement, dans un certain nombre de domaines, à faire appliquer leurs décisions. La volonté de restaurer l'autorité jusque dans la possibilité de faire exécuter ses décisions ne va pas absolument de soi dans une démocratie conçue sur le mode rationaliste car, idéalement, les individus devraient décider eux-mêmes directement de ce à quoi ils devront se soumettre (liberté-autonomie) et en référer à leurs propres facultés cognitives pour éclairer les décisions précédentes sans s'en remettre à quelque argument d'autorité que ce soit ${ }^{56}$. Mais comme la discussion de chacun avec chacun est vite matériellement impossible, il est assez vite nécessaire - on l'a vu - de transmettre à d'autres que soi le pouvoir de décider; et comme, de l'autre, les limites cognitives de tout individu sont vite atteintes et que chacun en conséquence ne peut être compétent sur tout, il est nécessaire de s'en remettre aussi ici à d'autres que soi. On pourrait dire, en s'en tenant encore à un usage intuitif des concepts ordinaires, qu'il est nécessaire, sur différents plans, de faire confiance à d'autres que soi, voire de s'en remettre à leur autoritée $e^{57}$. Mais ces concepts ordinaires eux-mêmes doivent, à leur tour, être mieux différenciés pour mener suffisamment finement l'analyse empirique.

La première distinction qu'il convient de rappeler est très classique mais elle n'est pas toujours utilisée de façon systématique: il s'agit de la différence entre pouvoir et autorité politique. La seconde, beaucoup moins usitée, est la distinction entre compétence et autorité cognitive (ou épistémique) mais elle devient capitale dès que l'on introduit l'idée de discussion argumentée et rationnelle. C'est aussi l'un des débats majeurs que l'on rencontre aujourd'hui dans la littérature sur la démocratie

${ }^{56}$ Le problème est à la fois au plan du rationalisme explicatif (quel modèle utiliser pour expliquer ce genre de phénomènes?) et au plan du rationalisme normatif. Sur le premier plan, voir note suivante; sur le second, on pourra se reporter à Kant (1947), Qu'est-ce que les Lumières? [1784], qui fait du droit et du devoir de penser par soi-même et d'exprimer publiquement sa pensée la devise des Lumières, droit et devoir qui n'excluent pas pour autant la soumission au pouvoir politique, lorsqu'il est jugé légitime, ce que Kant exprime un peu brutalement («Raisonnez [...] mais obéissez!», Kant, 1947, p. 48). Cette idée kantienne est souvent rappelée par les partisans de la démocratie délibérative ellemême (cf. Elster [1986], p. 121, Bohman [1997], p. X, Cohen [1997], p. 88). La pensée de Kant exprime un idéal. L'expérience montre qu'on est obligé de se contenter, si l'on peut dire, d'un second best qui fait sa place à l'autorité «épistémique» elle-même (cf. infra).

${ }^{57}$ La nécessité d'introduire des relations comme celles d'autorité et de confiance dans le cadre même d'une théorie sociale prenant pour noyau la théorie de l'action rationnelle est affirmée par Coleman (1990), respectivement au chap. 4 et au chap. 5 des Foundations et dans le cadre de la social epistemology par Goldman (1999). Toutefois Coleman ne s'étend guère sur la nature de la relation de confiance qu'il introduit. A partir de prémisses analogues, Hardin $(2000,2006)$ en vient à considérer que la confiance (au sens des relations de confiance interpersonnelles) ne peut avoir de place dans les relations entre les gouvernants et des gouvernés qui seraient rationnels (la rationalité commandant de ne faire confiance qu'à celui dont on sait qu'il a lui-même intérêt à se montrer fiable). Je suppose ici établi, d'une part, que la confiance politique excède effectivement la stricte rationalité (de même que l'autorité; cf. note précédente), d'autre part que la confiance politique est nécessaire. Voir l'intéressante discussion d'Albert Ogien (2005), qui compare notamment la théorie de la confiance de Hardin, fondée sur la recherche rationnelle du self-interest, et celle de Pettit, qui inclut une dimension morale. Si l'acceptation de relations d'autorité et de confiance fait problème dans le cadre de la conception de la liberté comme autonomie (cf. à nouveau la note précédente), elle fait en effet également problème dans le cadre de la conception de la liberté comme non domination (Pettit, 2004). 
dite délibérative ${ }^{58}$. Une analyse à peine plus poussée montre qu'il est utile de distinguer les relations d'autorité stricto sensu et les relations de confiance et, en conséquence, d'introduire les notions de confiance politique et de confiance épistémique. J'aborderai successivement l'analyse du niveau politique et du niveau épistémique.

Une remarque méthodologique: on peut penser que l'explication en sciences sociales au niveau microsociologique repose, en grande partie, sur des concepts et des principes descriptifs ou explicatifs qui ne sont pas très éloignés de ceux du sens commun - des topö̈-simplement analysés, explicités et codifiés, mais dont l'usage systématique et réglé permet de rendre saillants des phénomènes inaperçus ou de faire apparaître comme distincts des phénomènes régulièrement confondus entre eux ${ }^{59}$. Je me livre donc ici à une telle analyse, explicitation et codification (sur le mode de l'énumération) de ceux qui seront utilisés systématiquement dans la suite de l'analyse. Les principes en question sont, pour l'essentiel, des principes descriptifs, plus précisément des scénarios-types susceptibles de servir de «schèmes» pour décrire les processus particuliers à analyser.

\section{Pouvoir politique, autorité politique, confiance politique}

\section{a) Définitions: nature de l'autorité et de la confiance politiques}

Les analyses en termes de pouvoir, régulières en sociologie depuis au moins Marx, sont parfaitement légitimes comme toute modélisation, dès lors que celleci est bien faite, et elles sont parfois suffisantes. Mais elles laissent échapper quelque chose qui semble précisément ici en jeu: la question de la reconnaissance par ceux qui sont soumis au pouvoir en question (ou aux divers pouvoir en question) de la légitimité même de ce ou de ces pouvoirs. Il est raisonnable, en conséquence, de faire systématiquement la différence entre le simple pouvoir politique, d'un côté, et le pouvoir politique reconnu légitime, de l'autre, i.e. entre pouvoir politique et autorité politique ${ }^{60}$. Par pouvoir politique on entend ici tout à la fois

\footnotetext{
${ }^{58}$ Voir essentiellement Estlund (1997). Mais la question est aussi abordée par Michelman (1997), Johnson (1998) et Stokes (1998).

${ }_{59}$ Voir par exemple Elster (2003) et, spécialement sur le problème de l'autorité et sur la formulation et l'usage de topoï non triviaux nécessaires à l'explication de phénomènes sociaux paradoxaux, Elster (1990). Les phénomènes que j'ai ici à considérer n'ont pas, quant à eux, le caractère paradoxal et, à certains égards, fascinant de ceux que considère Elster (l'évergétisme romain, le totalitarisme soviétique, etc.).

${ }^{60}$ On pourra se reporter sur le thème de l'autorité à l'ouvrage désormais classique de D. Wrong (1979) (voir les commentaires de Braud [1985], pp. 381-382 et Chazel [1992], pp. 221-222), ainsi qu'à Habermas (1976,1978). Il faut se garder d'une expression comme «autorité politique légitime»; elle pourrait être un pléonasme ou bien simplement une redondance sans importance comme il en existe souvent dans la langue ordinaire; il vaut pourtant mieux la conserver pour désigner ce que peut énoncer un jugement philosophique extérieur sur une situation politique donnée: c'est en effet adopter une posture simplement sociologique que de remarquer que tel pouvoir est reconnu légitime par la population concernée par opposition à tel autre pouvoir (par exemple en Iran celui des Ayatollahs par opposition à celui du dernier Shah), donc qu'il a autorité sur cette population; mais c'est adopter une posture politique (et éventuellement philosophique, si elle est argumentée en remontant jusqu'à des principes normatifs), que de juger que cette autorité politique est en elle-même légitime ou non (par exemple rapportée aux droits de l'homme, au droit des femmes à l'égalité avec les hommes, etc.). Rousseau s'est soucié des deux plans, Weber se restreint par méthode, dans ses écrits sociologiques, au premier plan. Je m'en tiens moi-même ici au seul plan sociologique.
} 
pouvoir de décider et pouvoir de faire exécuter ses décisions. Je parlerai parfois aussi, en conséquence, pour des raisons stylistiques, de pouvoir décisionnel et d'autorité décisionnelle.

Mais l'autorité politique ne requiert pas seulement la reconnaissance de la capacité décisionnelle, elle requiert aussi la confiance, i.e. la croyance (fondée ou non) en l'honnêteté, au moins globale, de la personne en question ${ }^{61}$. Inversement, un homme politique peut susciter la confiance sans jouir pour autant de l'autorité politique: on le croit honnête, mais on ne le pense pas forcément apte à prendre des décisions d'ordre politique. La confiance politique repose donc sur la reconnaissance de qualités morales ${ }^{62}$. L'autorité, quant à elle, requiert la confiance mais aussi la reconnaissance de qualités simplement pragmatiques de décision et d'aptitude à faire appliquer ses décisions.

b) Les sources effectives de l'autorité et de la confiance politiques et de la perte de l'autorité et de la confiance politiques.

La question se pose, de façon générale, de savoir comment s'acquiert ou se perd cette légitimité acquise ou conquise par le ou les pouvoirs; il s'agit à première vue, pour les pays qui nous concernent, essentiellement de la légitimité de type rationnel-légal (pour utiliser la notion de Weber) ou légal (pour faire bref).

1. Dans nos sociétés, la légitimité, en effet, est généralement obtenue par des procédures légales, par exemple par les urnes, directement ou indirectement (élections politiques à plusieurs niveaux ou élections politiques suivies de nominations). Je parlerai d'autorité politique ou décisionnelle légale. Ce trait de l'autorité est bien exprimé en français par une expression comme: «X a autorité pour».

1bis. Parler sans plus de précision de l'autorité de l'Etat n'est souvent qu'une abstraction. Il faut en réalité ici distinguer les différents échelons de l'autorité politique légale, depuis le gouvernement jusqu'aux échelons inférieurs de l'administration (préfets, recteurs, maires); on parlera d'autorité administrative à leur propos. L'autorité des titulaires de ces fonctions est une autorité qui leur vient de celui ou ceux qui les ont nommés (et pour le premier élément de la chaîne au moins, d'une élection par le peuple); c'est donc une autorité déléguée.

1ter. On notera que le pouvoir politique, par le biais de l'administration, a autorité pour décerner diplômes et habilitations diverses donc pour certifier des compétences (cf. infra). C'est notamment le cas du ministre de l'Education nationale.

2. Le fait est, cependant, que les hommes politiques, même s'ils occupent également leur fonction en vertu de la loi (i.e. en excluant, par exemple, les cas de

${ }^{61}$ Cf. Pasquino (2006), n. 12 (dans ce volume même), qui cite la Rhétorique d'Aristote à propos du caractère essentiel de la confiance que doit inspirer celui qui veut persuader. Les critères de reconnaissance de cette honnêteté varient manifestement selon les sociétés et les périodes. Il n'est pas nécessaire, par ailleurs, d'être effectivement honnête pour être cru honnête; cf. les conseils de Machiavel au Prince ou ceux de Benjamin Franklin à ceux qui veulent pouvoir emprunter à leur banquier.

${ }^{62}$ On notera que c'est bien du concept de confiance morale dont nous avons besoin ici ou de ce qui entre de moral - ou plus exactement même d'apparemment moral - dans la confiance. Voir Pettit (1998). 
soupçon de fraude électorale ou même simplement d'incertitude dans la comptabilisation des voix ${ }^{63}$ ), ont les uns et les autres une légitimité inégale et, ce faisant, une autorité inégale, c'est-à-dire une aptitude inégale à faire appliquer leurs décisions. Il s'agit de l'autorité personnelle, celle qui tient au talent à prendre des décisions et à les faire exécuter (cf. 3$)^{64}$. Je parlerai, en conséquence, d'autorité politique ou décisionnelle personnelle ${ }^{65}$. Chaque niveau de pouvoir, quoique «autorisé» par le pouvoir supérieur, a ainsi besoin d'assurer sa propre autorité à son échelon ${ }^{66}$. Ce trait de l'autorité est assez bien exprimé en français par une expression comme: «X a de l'autorité».

3. On peut penser que le processus général de légitimation de l'autorité politique (avec ce qu'elle suppose de confiance) est en principe partout le même: reconnaissance initiale et informelle d'une aptitude à la décision puis, éventuellement, formalisation de celle-ci par un vote ou une procédure du même genre, puis éventuellement retrait de cette légitimité de fait, usure du pouvoir et éventuellement renversement du pouvoir en place, à moins que celui-ci ne préfère se maintenir par la force brute (c'est-à-dire en renonçant, au moins de façon provisoire, à être perçu comme légitime par les gouvernés) ${ }^{67}$.

3bis. Dans le but de rationaliser autant qu'il est possible la confiance que l'on met en des dirigeants ou l'autorité qu'on leur confère, il est habituel de chercher des sortes de «certifications», i.e. de garanties formalisées de la reconnaissance qu'on est en position de donner ${ }^{68}$.

4. On retrouve le schéma général précédent au sein des partis, des syndicats, des associations diverses, etc. (moins l'usage de la force brute qui relève de l'Etat ou, plus exactement, des chefs de l'armée) ${ }^{69}$ : là aussi, il y a des personnes dotées d'une certaine autorité obtenue en fonction de règlements ou d'usages internes (élections, par exemple), mais l'exerçant diversement en fonction du degré variable de leur autorité personnelle ${ }^{70}$, et étant susceptibles de perdre aussi l'une et l'autre.

${ }^{63}$ Comme dans le cas de la première élection de G. Bush Jr face à Al Gore.

${ }^{64}$ On peut considérer l'autorité charismatique selon Weber comme une variété d'autorité personnelle exceptionnelle; la notion wébérienne, qui pense l'exceptionnel, tend du même coup à cacher l'existence d'un phénomène autrement plus répandu et plus banal, mais du même type.

${ }^{65}$ Une belle question, théoriquement parlant, est celle de savoir comment se construit l'autorité «personnelle» lorsqu'on n'a pas à faire à un individu mais à un groupe. La compétence décisionnelle du groupe ne peut être simplement la somme de la compétence décisionnelle de chacun.

${ }^{66}$ Chaque ministre, chaque préfet, chaque recteur a une autorité légale au même échelon, mais l'autorité personnelle peut considérablement varier.

${ }^{67}$ Ainsi le Président G. Bush Jr dont l'autorité initiale était faible en raison d'une élection confuse a-t-il conquis une autorité considérable après l'attentat du 11 septembre 2001, autorité à nouveau affaiblie par l'enlisement en Irak de l'armée américaine.

${ }^{68}$ Les analyses consacrées plus spécifiquement à la confiance économique seraient probablement transposables à la confiance politique. Cf. le rôle des sectes protestantes aux USA au début du XX siècle pour conférer la réputation d'être honnête (Weber [2003]), le rôle des clubs comme le Rotary Club plus tard (Coleman [1990]).

${ }^{69}$ Encore qu'il y a souvent des services d'ordre plus ou moins «autorisés» par l'Etat dans les organisations conséquentes, ayant notamment pour but de canaliser les militants même de ces associations.

${ }^{70}$ Voire de leur «charisme». 
5. Comme l'autorité politique, la confiance politique se construit, s'use, se perd et, éventuellement, se reconquiert ${ }^{71}$.

6. Il peut évidemment résulter de ces variations de la confiance et de l'autorité politiques des conflits d'autorité et de confiance entre les «autorités» en place et les pouvoirs d'opposition reconnus par leurs militants (donc «autorisés» par eux), voire entre ces pouvoirs d'opposition eux-mêmes.

\section{Compétence cognitive, autorité épistémique et confiance épistémique}

\section{a) Définitions: nature de l'autorité et de la confiance épistémiques}

Quand on parle de l'autorité de quelqu'un, on ne pense pas nécessairement à un pouvoir (reconnu) de faire quelque chose; on peut penser aussi à un savoir. Les hommes politiques sont supposés capables de décider et de faire exécuter ces décisions par la force matérielle qui est mise en leur pouvoir et par l'autorité qui leur est donnée; mais si certains sont aussi dotés de savoir (et qu'ils le sont tous forcément à un degré ou à un autre), cela n'est pas absolument requis. Dans un cadre rationaliste, il importe aussi de pouvoir contrôler la confiance épistémique que l'on donne à quelqu'un ou l'autorité épistémique que l'on est prêt à lui conférer (et donc la «deference» que l'on est prêt à lui manifester, pour utiliser le terme même d'Estlund [1997]) $)^{72}$.

Et de même que le pouvoir politique et l'autorité politique ne sont pas identiques, de même la compétence effective et la compétence reconnue: quelqu'un peut avoir une grande compétence objectivement parlant dans un domaine, tandis que personne (ou peu de monde) ne croit qu'il la possède (par exemple parce qu'il n'a pas les attributs qui correspondent en général à une telle compétence $)^{73}$; inversement, quelqu'un peut avoir une compétence reconnue en un domaine, éventuellement une grande compétence reconnue et être objectivement peu compétent ${ }^{74}$.

Enfin, de même qu'il est utile de distinguer l'autorité politique de la confiance politique, même si celle-ci contribue à la première (prise lato sensu), de même il est utile de distinguer l'autorité épistémique de la confiance épistémique. Cependant, dans bien des cas, on parle de confiance épistémique dans des contextes où

${ }^{71}$ Cf. en France, le rôle des différents scandales politico-financiers liés au financement occulte des partis politiques, mais aussi celui de la gestion de l'affaire du sang contaminé par le gouvernement Fabius ou encore celui de la gestion du «nuage» de Tchernobyl par Giscard. Albert Ogien (2005, pp. 462-463) met bien en évidence cet aspect en se fondant notamment sur Pettit (1998 et 2004).

${ }^{72}$ Estlund (1997), p. 185.

${ }^{73}$ Il arrive aujourd'hui qu'une caissière de supermarché à temps partiel prépare une thèse de mécanique quantique ou soit diplômée de sciences politiques tout en ne pouvant guère espérer être reconnue dans son travail autrement que comme caissière.

${ }^{74}$ La figure-type en est le charlatan, mais il arrive aussi de temps en temps que l'on débusque, par exemple, des faux médecins (exerçant sans diplôme). Dans la même note déjà citée, Pasquino (2006) met en évidence explicitement le rôle de la confiance (politique) mais aussi, implicitement, celui de l'autorité épistémique, i.e. de la compétence cognitive reconnue (en l'occurrence la compétence technique et la compétence rhétorique) dans les débats argumentés au sein d'organes délibératifs (au sens juridique usuel, i.e aristotélicien) tels que le Conseil constitutionnel français ou la Cour de cassation. Mais la différence entre compétence et compétence reconnue n'est pas suffisamment faite dans la littérature. 
l'on veut signifier que des chercheurs appartenant à des disciplines différentes coopèrent ensemble; chacun a besoin des connaissances de l'autre parce qu'il ne les possède pas lui-même; on dit alors que chacun est sous «la dépendance épistémique» (Hardvig [1985]) de chaque autre ou qu'il lui fait «confiance» (Thagard [1997]). On dit aussi que chacun reconnaît à l'autre une compétence en son domaine, et que cet autre est donc en position d' «autorité épistémique».

Un terme suffisant pour une chose, on peut réserver le terme de «confiance épistémique» pour un type de relation que l'expression désigne parfois aussi (et parallèle à ce que désigne l'expression de confiance politique telle que nous l'avons définie): le rapport que l'on a à l'égard de quelqu'un que l'on croit intellectuellement honnête. Il ne s'agit donc pas ici d'une affaire de compétence mais d'une question éthique.

Le concept d'autorité épistémique ne suffit pas dans l'analyse: il faut encore le concept de confiance épistémique. Il ne suffit pas que l'on croie que quelqu'un connaît la vérité; il faut qu'on croie aussi que la connaissant, il la dira.

b) Les sources de l'autorité et de la confiance cognitives ou épistémiques.

Une question analogue à celle qui se posait à propos de l'autorité et de la confiance politiques se pose concernant l'autorité et la confiance épistémiques: celle de leur source et de l'éventuel tarissement de cette source.

1. Dans nos sociétés, l'autorité épistémique est généralement transmise par des diplômes, i.e. que la compétence est en général reconnue par une autorité administrative (cf. supra).

1bis. Il peut cependant y avoir encore une différence considérable entre une compétence livresque ou de laboratoire et une compétence en acte ou sur le terrain $^{75}$.

2. L'autorité épistémique d'un individu dépend aussi de son aptitude personnelle à montrer cette compétence. Le professeur de mathématiques, même bien diplômé, qui est régulièrement conduit à effacer le tableau parce qu'il s'est trompé dans ses calculs, perd une bonne part de son autorité épistémique auprès des élèves; l'ingénieur qui ne sait pas répondre à une question technique relevant de son domaine également.

3. On peut construire ce schéma très simple de genèse de l'autorité épistémique d'un individu: celui-ci acquiert des compétences dans un domaine donné de façon «auto-didacte», i.e d'une façon qui n'a nécessité aucune transmission de connaissances de la part de quelqu'un d'autre quant à ce qui est en question. Pour acquérir une autorité épistémique en la matière auprès de quelqu'un, il faudra et il suffira probablement d'avoir fait la preuve un certain nombre de fois (variable selon la rigueur des «juges») de sa compétence dans des domaines où des spécialistes ou des demi-spécialistes étaient capables d'en juger (par exemple par le

${ }^{75}$ Ainsi oppose-t-on depuis un certain temps «savoir de plein air» versus «savoir confiné», avec des dénominations axiologiquement très marquées et, par là, un peu démagogiques (Lascoumes, Callon, Barthe, 2001). 
résultat). Ceux-ci se sentiront fondés à conférer à l'autre une «autorité» épistémique en la matière - en procédant en quelque sorte par généralisation inductive.

Le procédé logique sera un peu différent si la personne en question est déjà dotée d'une telle autorité, i.e. si d'autres personnes (ou d'autres instances, par exemple l'autorité administrative) ont déjà garanti qu'il a bien la compétence en question. En ce cas, le schéma suivant est vraisemblable: la personne est a priori dotée de l'autorité épistémique en question mais de façon provisoire; la compétence ne doit pas être trop souvent mise en défaut. Comme l'autorité politique, l'autorité épistémique n'est en effet jamais acquise une fois pour toutes.

3bis. On peut prolonger le scénario précédent: comme le procédé est long et coûteux en temps et en énergie, on a inventé des formes de certification de la compétence. Il faut imaginer au début de la chaîne quelqu'un qui ne peut «s'autoriser que de lui-même», i.e. en fait qui a fait la preuve de sa compétence suffisamment pour que les autres lui aient accordé leur confiance en ces matières. Dans une société plus structurée, les citoyens élisent des gouvernants qui nommeront eux-mêmes les autorités épistémiques susceptibles de décerner les certificats en question ${ }^{76}$.

3ter. En outre, en dehors des certificat de compétence générale, lesquels sont le plus souvent acquis une fois pour toutes ${ }^{77}$, il y a des habilitations ad hoc et temporaires de personnes particulières parmi les personnes déjà diplômées. Ainsi estce cas pour les divers experts à la Cour: psychiatres, graphologues, etc. Cela ne veut pas dire que leur compétence est reconnue plus grande, mais que seuls leurs rapports pourront être juridiquement pris en compte dans les débats.

4. On peut raisonnablement penser que comme l'autorité épistémique, la confiance épistémique se construit, s'use et se perd. Il est plus douteux qu'elle puisse se reconquérir ${ }^{78}$.

5. Il peut résulter de ces variations de la confiance et de l'autorité épistémique des conflits d'autorité et de confiance, sur différents plans que l'on peut commodément distinguer et dont Alvin Goldman $(1999,2002)$ a notoirement analysé certains traits: par exemple entre experts dont la compétence est également recon-

${ }^{76}$ Le débat récent en France concernant la question d'une législation encadrant la profession de psychothérapeute a notamment été suscité par l'existence de l'école lacanienne dans laquelle chaque analyste était supposé s'autoriser de lui-même sans y être autorisé ne serait-ce que par une instance interne à l'école. L'histoire de la psychanalyse, hormis cette école particulière, donne une illustration typique de cette séquence d'autorisations épistémiques en chaîne à partir d'une unique source: Freud est le seul à s'être autorisé de lui-même (puisque le seul, en principe, à être analyste sans avoir été analysé par un autre analyste) et l'autorité épistémique de tous les autres remonte jusqu'à lui par une chaîne d' «autorisations», dont on pourrait aisément compter les chaînons.

77 On ne repasse pas ses examens; cependant la «qualification» à exercer dans le grade convoité lorsque l'on est candidat à un poste de maître de conférence ou de professeur n'est pas, dans le système universitaire français contemporain, acquise une fois pour toutes. La cohérence (mais non pas la paix sociale dans les universités) voudrait que cette qualification des universitaires déjà élus soit réexaminée régulièrement tout au long de leur carrière; cela devrait s'imposer dans les disciplines où la vie où l'intégrité d'autres personnes est en jeu (médecine, chirurgie).

${ }^{78}$ Quelqu'un convaincu d'une fraude dans ses expérimentations pourra-t-il encore convaincre ses pairs sur quelque sujet que ce soit? Un architecte qui fait une erreur majeure de conception ayant pour conséquence l'effondrement d'un bâtiment se verra-t-il encore confier des projets? 
nue par une autorité politico-administrative ${ }^{79}$, mais aussi entre, d'un côté, experts dont la compétence est reconnue par une autorité politico-administrative et, de l'autre, experts dont la reconnaissance consiste uniquement dans celle qui vient des profanes, etc. Ces problèmes spécifiques ont donné lieu tout récemment à de nombreuses analyses en sociologie, mettant notamment en cause la division trop tranchée entre experts et profanes ${ }^{80}$.

\section{LA DYNAMIQUE DES RELATIONS DE CONFIANCE ET D'AUTORITÉ} DANS LE DÉBAT PUBLIC 1997-1998 EN PROVENCE-CÔTE D’AZUR

Muni de ces clarifications conceptuelles et de ces scénarios-types, nous pouvons enfin aborder dans le détail la question essentielle qui est posée par l'instauration récente de formes de démocratie de proximité dans lesquelles le débat argumenté - sinon la délibération - joue un rôle central, à savoir celle de la façon dont le pouvoir politique officiel central - l'Etat - réussit à exercer son autorité politique, et éventuellement à restaurer celle-ci, sachant que cette autorité politique suppose, au moins en nos sociétés, que soit reconnue aux détenteurs du pouvoir ou, au moins, à leurs conseillers une compétence cognitive, donc que l'Etat ou ses représentants aient aussi une autorité épistémique. Si l'on suppose les acteurs rationnels ou au moins tendant à la rationalité et les schèmes précédemment formulés vraisemblables, on peut dire a priori que cette autorité politique et cette autorité épistémique ne seront pas octroyées une fois pour toutes, mais qu'elles ne seront pas non plus forcément dissoutes définitivement lorsqu'elles seront ébranlées. Mutatis mutandis, on peut en dire à peu près autant de la confiance politique et de la confiance épistémique.

On peut pressentir que ce qu'on appelle simplement, dans une approche globale, le problème de l'autorité du pouvoir politique doit être décomposé en un nombre étendu de relations diverses (d'autorité politique, de confiance politique, d'autorité épistémique, de confiance épistémique) entre des partenaires euxmêmes nombreux et parfois finement hiérarchisés (penser aux chaînes hiérarchiques des administrations) et que la structure de ce réseau serré et enchevêtré mais fragile est lui-même susceptible de modifications, voire de torsions considérables tout au long du processus du débat ${ }^{81}$.

\footnotetext{
79 A. Goldman $(1999,2002)$ s'est spécialement intéressé à ce cas-type.

${ }^{80}$ Mais parfois la distinction a été éliminée si radicalement qu'il est difficile de ne pas y voir là aussi un procédé démagogique (Lascoumes, Callon, Barthe [2001]).

${ }^{81}$ La durée de celui-ci est fixée par la loi (4 mois normalement, 6 au maximum si une contreexpertise est décidée). Le débat public Boutre-Carros a duré 6 mois. Concrètement, il a pris trois formes: d'une part des assemblées générales qui se sont tenues à chaque fois dans des villes différentes de manière à ce que le plus grand nombre possible de «riverains» potentiels participent au moins une fois à l'une de ces AG (ce qui signifie aussi que seule une poignée de personnes, par définition les plus militants, ont participé à l'ensemble de ces AG), d'autre part des tables rondes techniques consacrées à des thèmes particuliers et dont la spécificité était de faire intervenir des experts, enfin une Lettre du débat, dans laquelle on pouvait trouver un compte-rendu très détaillé des AG et TR avec de larges extraits des interventions ainsi qu'un courrier des lecteurs auquel répondaient systématiquement les membres de la commission. Naturellement, les participants discutaient aussi «hors débat», y compris
} 
Le débat qui s'est tenu en Provence-Côte d'Azur en 1997-8 fournit un matériau suffisamment riche pour examiner la dynamique de cette structure complexe de micro-relations. Ce débat portait sur la pertinence de l'installation d'une ligne à très haute tension - et éventuellement sur le tracé de cette ligne - censée garantir l'alimentation en électricité d'une grande partie de la Côte d'Azur par le doublement de la ligne littorale existante, constamment menacée en été par les incendies de forêt, par une ligne située nettement plus au Nord dans l'arrière-pays mais passant nécessairement par des paysages de qualité, comme le Parc naturel régional du Verdon et provoquant en conséquence à l'évidence des nuisances, au moins esthétiques, pour les riverains de la ligne en question (sans avantage direct pour eux $)^{82}$. Des débats de ce type se sont généralisés, de la pertinence de construire un troisième aéroport en région parisienne à celle de mettre en place un métro dans telle ou telle ville, etc.

Par souci pédagogique, je suivrai ici pour l'essentiel la chronologie du débat et distinguerai en conséquence une série de séquences - la première remarque mise à part.

1. Un des aspects du débat public qui s'est tenu en Provence-Côte d'Azur en 1998 est aujourd'hui caduc puisque la loi de 2002 l'a modifié ${ }^{83}$. Aucune structure ne prévoyait que les arguments des opposants au projet soient pris en compte dans la délibération (stricto sensu) des ministres ou des cabinets des ministres concernés. Et il ne semble même pas que l'on ait conçu à ce moment-là - mais il faut se souvenir de la relative précipitation de la législation à cette époque - que des informations utiles puissent venir des riverains.

Même si on laisse de côté les interprétations maximalistes latentes au cours du débat, qui tendaient à voir dans une série de rencontres une assemblée potentiellement non seulement consultative mais délibérative, il est clair que les participants au

avec les promoteurs de l'ouvrage ou les membres de la commission. De ces «arènes» par nature inorganisées, je ne traite pas du tout ici. On trouvera des informations complémentaires sur ce débat dans la contribution très informée de Jean-Michel Fourniau (2006), dans ce même volume.

${ }^{82} \mathrm{~J}$ 'ai travaillé essentiellement à partir du dépouillement in extenso des 16 Lettres du débat public (500 pages) du 15 mars 1998 au 15 septembre 1998. J'avais été contacté par le cabinet Moser et Malt, chargé de la conception et de la réalisation de la Lettre du débat public au tout début de 1999, pour faire une analyse de l'échange d'arguments, effectuée sous la forme d'un (modeste) rapport remis en juillet 1999. J'ai tiré parti, à cette époque, d'un certain nombre de rencontres avec les membres de ce cabinet, qui avaient suivi le débat de bout en bout. J'ai beaucoup appris aussi, lors de diverses rencontres ultérieures - rencontres privées ou à l'occasion de colloques divers échelonnés sur plusieurs années et prenant régulièrement comme référence ce débat-type - d'un des ingénieurs EDF adjoints de la directrice de projet pendant le débat et auteur d'un rapport très substantiel sur ce même débat pour le compte d'EDF, Jean-Paul Puyfaucher (2002). Grâce à J.-M. Fourniau (dont le rapport sur ce débat, rédigé dès 1998, m'a été utile), j'ai aussi pu rencontrer lors d'un séminaire spécifique sur le même sujet en mai 2004 l'un des principaux acteurs du débat du côté des opposants, Jean Gonella. Parmi les divers documents consultés à titre comparatif, j'ai trouvé particulièrement utile l'excellent rapport dirigé par Laurence Monnoyer-Smith (2005), consacré au dispositif original de concertation mis en place en 2001 sur le choix de l'implantation d'un troisième aéroport en région parisienne (notamment le survey des pp. 27-52). J'ai traité du débat Boutre-Carros sous divers aspect dans divers articles, communications et conférences. Voir notamment A. Bouvier (2004).

${ }^{83}$ Avant la loi de 2002, en effet, on l'a vu, les débats de type loi Barnier n'avaient cependant pas même valeur consultative. 
débat de 1998 espéraient, même conscients de ce que le simple pouvoir consultatif ne leur était pas reconnu, que leurs voix auraient néanmoins d'une manière ou d'une autre un impact. C'est évidemment la raison (sauf à supposer une improbable erreur de jugement massive de la part de nombre de participants) pour laquelle un certain nombre d'entre eux se sont autant mobilisés pour réussir à faire ordonner une contre-expertise qui ébranlât voire renversât les conclusions de la première expertise, ce que la loi de 1995 autorise puisque cette loi autorisait la mise en place d'une telle contre-expertise dans le cas où preuve est faite que toutes les solutions alternatives n'ont pas été envisagées ${ }^{84}$. De fait, on peut dire que les arguments ont, in fine, été entendus - non pas par le gouvernement, mais par le maître d'œuvre de l'ouvrage projeté, en l'occurrence EDF, puisque EDF, proposera après la fin du débat un autre projet, alors même que la loi, à strictement parler, ne l'exigeait nullement ${ }^{85}$. Ces arguments ont même été entendus, en réalité, avant la fin du débat par la Commission particulière du débat public elle-même. Mais ce serait trop anticiper ici que d'exposer dans le détail ce moment du débat avec tous ses attendus.

D'un autre côté, il est non moins clair que, même dans le cadre de la seule loi de 1995, le fait de demander leur avis aux riverains est significatif quant à la façon dont l'Etat (le pouvoir exécutif) percevait les représentants du peuple en général conseillers généraux, députés, sénateurs - puisque l'une de leurs fonctions est de faire remonter au niveau du pouvoir national (notamment au Parlement mais aussi lors des multiples réunions de concertation avec les ministres ou leurs directeurs de cabinet ou encore dans les diverses commissions de l'Assemblée nationale et du Sénat) les revendications de leurs électeurs, même si, en principe, les représentants du peuple doivent ensuite voter les lois en fonction du bien public, i.e. du bien du pays dans son ensemble (c'est le problème de Sieyès) et éventuellement en référence à des valeurs (par exemple dans le cas de l'abolition de la peine de mort). On pourrait dire que le recours à ces formes directes de consultation témoigne implicitement de la part du pouvoir central de la prise de conscience de la perte de représentativité de ces «grands élus» et de l'effort pour assurer la représentation des intérêts des citoyens par d'autres voies (ce qui ne peut au premier abord que déplaire aux élus, mais est cependant inéluctable vu le nombre et la spécificité des problèmes particuliers rencontrés par l'administration d'un pays complexe $)^{86}$.

${ }^{84}$ Parler de l'autorité de la loi est évidemment une manière conventionnelle abrégée de désigner l'autorité des législateurs, lesquels ne l'ont, en dehors des régimes fondés sur la force pure ou la menace de l'usage de la force pure (la terreur), que parce que ceux sur lesquels ils exercent le pouvoir considèrent légitime celui-ci.

${ }^{85}$ Ce qui veut dire que certains des arguments des opposants ont été pris en charge par les représentants d'EDF et que ceux-ci ont délibéré et ont clos cette délibération par la prise la décision de modifier la nature du projet.

${ }^{86}$ Il s'agit d'un problème symétrique de celui de l'autorité; il est peut-être encore plus grave, car si les représentants du peuple ne représentent plus effectivement le peuple - ou, au moins, sont perçus comme ne représentant plus efficacement celui-ci -, il est improbable que l'Etat conserve une quelconque autorité lorsqu'il voudra appliquer les lois décidées par ces représentants ou les décrets et règlement divers qui en sont des conséquences ou des applications (sur ce problème, voir les excellentes analyses de Gargarella [1998] et ses remarques pénétrantes sur la façon dont doivent s'associer exigence de délibération au niveau parlementaire et exigence de pleine représentativité des parlementaires). Dans les faits, le principe de la consultation directe du peuple sur les questions 
Il n'est pas impensable non plus que les conseillers généraux, députés et sénateurs (les «grands élus»), aient été négativement sensibles aux discours maximalistes vantant la démocratie participative (avec ce que la notion suppose au minimum de «clin d'œil» vers la démocratie directe) et aient perçu dans les débats publics de type loi Barnier une sorte de première étape d'une remise en cause du système représentatif lui-même, mettant en cause leur fonction même et donc l'autorité politique légale qui leur était transmise par leur élection ${ }^{87}$, au-delà de la remise en cause de leur seule manière de s'acquitter de leur fonction, i.e. de leur autorité politique personnelle. Ces deux hypothèses rendent compte en tout cas de la très faible présence - remarquée - des grands élus au cours du débat en PACA (le plus présent est, de loin, Maurice Janetti, député du Var, en tant que porteparole de la coordination des élus et des associations $)^{88}$.

2. La situation de départ. Reprenons maintenant la chronologie du débat en commençant par dresser un bref inventaire des différentes instances en présence au début du débat et dotées d'une autorité d'un ordre ou d'un autre - ou la recherchant - et jouissant d'une confiance d'un ordre ou d'un autre - ou la recherchant.

a) Il n'y a pas de représentant du gouvernement en tant que tel au sens d'une instance chargée de faire valoir le point de vue du gouvernement, i.e. en principe le point de vue du bien public. Ce serait pourtant imaginable, puisque l'intérêt de la ligne à THT ne concerne bien entendu pas que les riverains de la ligne mais bien d'autres catégories d'usagers, en l'occurrence ceux qui habitent sur le bord de mer et sont particulièrement sensibles aux ruptures impromptues de courants dues aux incendies (industriels, directeurs d'hôpitaux et cliniques, directeurs d'hôtels) ou y résident temporairement (touristes - en nombre sur la côte) et sont les principaux bénéficiaires de l'ouvrage projeté.

b) A la place, en quelque sorte, il y a un maître d'œuvre, EDF, qui, à l'époque, est une entreprise nationalisée et qui reçoit donc ses ordres indirectement (i.e. à la suite d'une chaîne de nominations de personnes dotées de compétences décisionnelles légales particulières) du gouvernement lui-même et sera donc autorisée par lui à décider dans des limites très restreintes (techniques) lorsque le projet aura été définitivement avalisé par le gouvernement. Son rôle est pour le moment de convaincre les riverains du bienfondé du projet que le gouvernement l'a chargé de préparer (bien-fondé du projet et, éventuellement, choix du tracé entre plusieurs options). Ce que

touchant aux intérêts riverains d'un grand projet existe depuis longtemps sous la forme, notamment, de l'enquête d'utilité publique. La loi Barnier visait à mettre en application ce principe de façon nettement plus consistante.

${ }^{87}$ Cf. note précédente.

${ }^{88}$ Ces hypothèses sont confirmées par des témoignages de participants au débat; mais il aurait fallu pouvoir conforter ces témoignages par des interviews systématiques des personnes concernées au moment du débat ou peu après. Tous les observateurs ont, par ailleurs, noté que l'attitude des élus a beaucoup changé dans les débats publics ultérieurs dans la mesure où les élus, en général assez flexibles par nature dans leur manière de parvenir au pouvoir ou de s'y maintenir, ont assez vite perçu les avantages qu'ils pouvaient tirer de leur participation auxdits débats. 
l'entreprise nationalisée doit obtenir et conserver, c'est l'autorité épistémique sur les participants au débat, notamment les opposants, i.e. la reconnaissance de ce que ses agents sont compétents, et la confiance épistémique, i.e. la reconnaissance de ce que ses agents sont honnêtes quand ils s'expriment. L'autorité épistémique doit s'exercer sur les participants au débat mais aussi sur ceux qui ont pour unique fonction de veiller au bon fonctionnement de celui-ci, i.e. la Commission particulière du débat public; et la confiance épistémique doit elle-même être obtenue des uns et des autres. Cela ne va pas forcément de soi, comme on va le voir.

c) Il y a en outre, comme on l'a vu, nommée par une Commission nationale du débat public, elle-même nommée par le gouvernement, une instance dont le rôle n'est nullement de faire valoir le point de vue du gouvernement, mais uniquement d'organiser matériellement le débat et notamment - point essentiel dans l'application de ce que j'ai appelé le principe de la discussion argumentée - de faire respecter les normes d'une bonne argumentation: la Commission particulière du débat public ${ }^{89}$. Il s'agit bien d'un pouvoir décisionnel qui est donné à la commission mais uniquement sur le cours du débat (elle a, par délégation du pouvoir central, une autorité légale sur le cours du débat). Cette autorité est loin d'être négligeable, puisque la commission a notamment autorité pour décider de commander une contreexpertise dans le cas où l'expertise première s'avèrerait défectueuse; et il revient à la seule Commission de juger si preuve de cette défectuosité est effectivement faite ou non. Dans le cas du débat de 1998 en PACA, la Commission usera de cette autorité conférée par le gouvernement.

Mais ce dont doit disposer d'emblée cette commission à son tour - ou sinon ce qu'elle doit conquérir - c'est une autorité propre sur les différents membres participant au débat, i.e. sur les opposants et sur les représentants d'EDF eux-mêmes, qui sont soumis aux mêmes règles procédurales ${ }^{90}$. De fait, elle usera de cette auto-

${ }^{89}$ Son président, Gérard Porcell, accomplira cette tâche spécifique de différentes manières. Par exemple, en rappelant à l'ordre le député du Var, Maurice Janetti (porte-parole des élus et des associations), avant même le début du débat public, fixé le 15 mars, dans une lettre du 24 février répondant à une lettre du député du 26 janvier et publiées l'une et l'autre dans la Lettre du débat public $\mathrm{n}^{\circ} 2$, du 2 avril 1998. M. Janetti affirmait «une opposition fondamentale et définitive [à] ce projet» (p. 6). G. Porcell demande une «critique argumentée» des études déjà effectuées par EDF, et rappelle plusieurs fois l'exigence d'argumenter (pp. 7-9). Plus tard, il condamne les «autodafés (sic) de documents de la Commission»: «Je n'apprécie pas qu'on brûle des écrits, quels qu'ils soient. Si on veut les combattre, que ce soit par des arguments. Et le débat public est le lieu pour le faire» (Lettre du débat public, n 7, p. 27). Plus tard encore, sans viser personne en particulier: « Pour ma part, je préférerais qu'on développe ici des arguments et qu'on garde les slogans pour plus tard, car ils sont des armes de rapport de forces et non celles d'un débat démocratique véritable» (Lettre du débat public, $\mathrm{n}^{\circ} 11, \mathrm{p} .14$ ). Un des membres de la commission, Maurice Parodi, avait justifié la norme et les moyens de la mettre en œuvre dans une autre Lettre: «Les tables rondes servent à affiner les argumentations de part et d'autre, pour que nous arrivions à une solution la plus cohérente et la plus persuasive possible, à l'intention des décideurs que seront forcément les ministères intéressés» (Lettre du débat public, $\mathrm{n}^{\circ} 5, \mathrm{p} .8$ ).

${ }^{90}$ On est ici en face ici du problème de l'autorité «personnelle» d'un groupe (cf. supra). En l'occurrence, comme la Commission est hiérarchisée et que c'est presque toujours son président qui s'exprime au nom de la Commission (même si les autres membres interviennent de temps en temps), 
rité décisionnelle, notamment à l'égard d'EDF, à deux reprises: d'une part en demandant à EDF de mettre en œuvre une contre-expertise, d'autre part au cours d'une séquence sur laquelle je vais revenir, en demandant à EDF de lui soumettre (à huis clos) le contenu d'un contrat commercial signé antérieurement avec l'Italie dans un contexte où les opposants au projet doutaient de la sincérité d'EDF quant aux motifs allégués pour justifier la construction de la ligne à THT -i.e. à un moment où la «confiance épistémique» mise en la direction d'EDF et en ses représentants par les opposants au projet était à peu près ruinée («EDF nous ment!»). Mais le fait que EDF ait accepté de révéler la nature réelle de ses contrats avec l'Italie (au moins a-t-il semblé à la commission qu'elle l'avait fait) manifestait, d'un autre côté, que les représentants d'EDF avaient confiance, quant à eux, en chacun des membres de la Commission, puisque ceux-ci auraient très bien pu individuellement, en dehors du débat public ou après le débat public, utiliser à des fins toutes personnelles ces informations $^{91}$. Enfin, le fait que la commission ait cru les informations que lui donnait EDF montre réciproquement qu'elle a eu épistémiquement confiance dans les représentants $d^{\prime} E F^{92}$. Je n'en dirai pas plus de ces rapports d'autorité et de confiance parce qu'ils ont été accordés d'emblée et qu'ils n'ont pas été remis en cause.

En revanche, pour que les conclusions du huis clos entre EDF et la Commission soient crus par les opposants au projet EDF, il fallait aussi que la commission ait la confiance épistémique des opposants - ce qui n'était pas acquis au début, et je reviendrai donc sur l'examen de ce processus - sans parler de ce qu'il fallait aussi que les opposants aient un minimum de confiance épistémique en ce que EDF disait à la commission en huis $\operatorname{clos}^{93}$.

d) Il y a une série d'experts spécialisés dans des domaines divers (dont l'esthétique du paysage), dont l'autorité et la confiance épistémiques devraient a priori être considérées; il se trouve que, dans ce débat, elles n'ont pas été spécialement contestées, probablement parce qu'elles ne touchaient pas à des questions perçues comme très sensibles. Je ne m'y arrête donc pas.

e) Il y enfin les opposants ${ }^{94}$. La modélisation proposée dans la partie précédente de cet article avait parmi ses ambitions de mettre en évidence qu'il y

l'autorité propre de la Commission, c'est en fait presque exclusivement l'autorité personnelle de son président, Gérard Porcell.

${ }^{91}$ C'est évidemment un risque constant dans les Conseils d'administration, les ministères, etc. et, en général, dans tous les huis clos.

${ }^{92} \mathrm{Si}$ l'on veut être très exact, il faut dire: les membres de la Commission ont décidé collectivement de donner à croire qu'ils croyaient collectivement que EDF disait la vérité; cela laisse la porte ouverte à la question de savoir ce que, en son for intérieur, chacun croyait vraiment. On ne sait rien, en outre, de la façon dont la Commission prenait ses décisions: délibérait-elle par exemple sur le modèle de Pasquino (2006) et Urfalino (2006), i.e. en recherchant un consensus par simple échange d'arguments? L'autorité personnelle du président sur les membres mêmes de la commission était-elle analogue à celle de Robert Badinter sur le Conseil constitutionnel, de sorte qu'il était psychologiquement difficile de s'y opposer (cf. Pasquino, 2006)? Mais on n'en sait pas davantage sur la façon dont les représentants d'EDF élaboraient une décision commune.

${ }^{93}$ Il se trouve que ce dernier point n'a jamais fait problème, curieusement peut-être, en tout cas au niveau de ce qui a été explicitement dit ou écrit dans le cadre du débat public.

94 Il n'y avait pas de représentants des partisans de la ligne THT (en tout cas, ils ne se sont à aucun moment signalés comme tels ni exprimés au sein des débats oraux, à une exception près), très proba- 
a aussi des phénomènes d'autorité - et bien entendu de confiance - internes à de simples associations. On s'en aperçoit ici aisément. Les opposants sont en effet, pour une bonne part, réunis au sein d'associations diverses et plusieurs intervenants parlent au nom de ces associations. Ce sont donc des «élus», mais des élus d'associations. Certaines sont des associations qui préexistaient au débat (associations écologiques ou associations de loisirs telles que, par exemple, une association de protection des lacs du site du Verdon, où l'on pratique la planche à voile, et un club de vol à voile), d'autres sont des associations ad hoc, parmi lesquelles certaines représentent un nombre très limité de personnes (parfois 4 ou 5 personnes actives) ou encore des fédérations d'associations (comme la FARE-Sud). Néanmoins, le seul fait de parler au nom d'une association d'opposants dote celui qui s'exprime du bénéfice d'une forme de confiance politique auprès des autres opposants, laquelle prédisposera à la confiance épistémique de la part des mêmes opposants (sans s'y substituer). Mais les leaders des opposants ne sont pas forcément uniquement des leaders ni des membres d'associations. Ils peuvent aussi, en même temps, être des «petits élus», i.e. des maires de petites villes ou des conseillers municipaux; et la dualité de leur fonction leur confère, du même coup, un type d'autorité non seulement mixte mais parfois contradictoire.

Ce sont les relations d'autorité (et de confiance) entre les opposants qui vont jouer le rôle déterminant dans le cours du débat, à une exception près (en faveur de la confiance en la Commission, conquise - on l'a signalé - au cours du débat) et c'est elles que je vais être en conséquence amené à considérer essentiellement dans ce qui suit. Mais pour que les arguments des opposants soient entendus par les représentants d'EDF, il a fallu que les opposants ou certains d'entre eux au moins conquièrent la confiance épistémique d'EDF (i.e. notamment ne soient pas perçus comme cherchant à biaiser les informations pour constituer un front d'opposition à EDF), voire se voient investis par EDF d'une certaine forme d'autorité épistémique en certaines matières, pour être simplement écoutés, ce qui ne sera pas chose aisée (a priori un expert en électricité d'EDF a du mal à imaginer que quiconque d'autre qu'un de ses pairs puisse non seulement faire des propositions intéressantes dans son propre domaine mais même comprendre réellement les propres solutions que lui-même propose). Il a fallu aussi que les opposants conquièrent la confiance de la Commission particulière pour convaincre celle-ci

\footnotetext{
blement parce qu'ils avaient peur d'être pris à partie (dans la mesure où il n'y avait pour eux que des avantages et aucun inconvénient à la construction de cette ligne; dans le langage de la théorie des jeux, on dirait que le gain était tout entier pour l'un des «joueurs» et la perte tout entière pour l'autre). Il y en avait pourtant un grand nombre (dans l'ensemble, les résidents du bord de mer). En revanche, les principaux intéressés (les industriels, notamment ceux de l'industrie chimique, très gros consommateurs d'électricité en raison surtout de l'usage de l'électrolyse, et très sensibles aux coupures de courant) se sont exprimés par courrier par l'entremise de la Chambre de commerce et d'industrie NiceCôte d'Azur. Dans les faits, c'est EDF qui était leur porte-parole, mais indirectement puisque au seul nom de la défense de l'intérêt public. Les seuls partisans de la ligne à s'être exprimés oralement dans le débat public sont les salariés CGT d'EDF, qui ont évidemment un intérêt tout personnel à la construction de cette ligne (Lettre du débat, $\mathrm{n}^{\circ} 16, \mathrm{pp} .27-28$ ).
} 
de la pertinence d'ordonner une contre-enquête, sachant que les arguments étaient d'ordre technique et que les membres de la commission n'étaient pas a priori compétents pour juger eux-mêmes en connaissance de cause (i.e. en se fiant à leur propre raison ou à leur propre expérience en la matière).

On verra enfin que les associations d'opposants n'étant pas organisées selon le même genre de relations, les relations de confiance ou d'autorité peuvent y être fort dissemblables. Le fonctionnement des Verts du Var va présenter, de ce point de vue, un cas d'école particulièrement intéressant.

\section{Première étape significative}

La première étape significative du point de vue de la construction ou/et de la mise à l'épreuve des relations d'autorité et de confiance entre les différents protagonistes du débat est la mise en cause de la sincérité d'EDF dans son implication dans le débat puisque EDF est supposée négocier «en coulisse» avec les maires ou certains conseilleurs municipaux des communes concernées (il s'agit, par exemple, d'envisager la construction d'un gymnase en compensation de la construction de la ligne) et de chercher à séduire les journalistes en leur faisant parcourir le parc du Verdon en hélicoptère (ce qui rentre dans ce que certains appellent une opération «marketing»). La première étape est, en réalité, plutôt une séquence entière (dans la mesure où le même thème intervient régulièrement au cours du débat), dont le premier acte prend place dès le début du débat. La méfiance s'étend inévitablement à ces élus qui peuvent en même temps être des leaders d'associations opposées à l'installation de la ligne à très haute tension; elle affectera l'appréciation de leurs prises de parole ultérieures ou de leur conduite après le débat en tant qu'opposants ${ }^{95}$. Les personnes en question (à la fois maires et leaders d'associations d'opposants) sont effectivement partagées car, d'un côté, elles voient les inconvénients de la ligne pour eux et leurs concitoyens, mais de l'autre elles en voient aussi les avantages en termes de biens collectifs.

Pourtant, la suspicion était juridiquement infondée puisque ces «négociations» non seulement étaient prévues par la loi mais constituaient même une sorte d'acquis des riverains, puisqu'elles constituaient des compensations. Sur le fond néanmoins, la suspicion peut difficilement être considérée comme sans pertinence: la loi aurait pu exiger que de telles discussions soient, par exemple, menées au sein même du débat ou bien qu'elles ne commencent qu'à l'issue du débat. Il en résultera une méfiance diffuse à l'égard d'EDF et de certains élus tout au cours du débat mais pas au point de provoquer un arrêt du débat. La commission ne pourra ici que rappeler la loi et rappeler qu'elle n'a pas autorité (ce pouvoir ne lui est pas octroyé par l'Etat) pour empêcher les négociations incriminées (au demeurant parfaitement licites) de continuer. Le résultat n'est pas que la Commission devient elle-même l'objet de méfiance - personne ne lui reprochant de cautionner

95 Significative est à cet égard la dernière Lettre du débat public ( ${ }^{\circ} 16,15$ sept. 1998), puisque sont rapportées dans la même page (p. 33) deux interventions faites lors de la réunion de clôture le 12 sept. 1998 par Raphaël Scipion (l'acteur du débat peut-être doté de l'autorité politique personnelle la plus «charismatique», mais en qui la confiance politique des opposants semble avoir été ébranlée), l'une en tant que président de l'Association Vivre en Haute-Provence, l'autre en tant que conseiller municipal de Moustiers-Sainte-Marie s'exprimant au nom du maire de la commune. 
illégitimement une sorte de double jeu. Ce qu'on peut dire néanmoins, c'est qu'elle n'a pas non plus, à cette occasion, gagné la confiance des participants au projet (sauf peut-être celle des représentants d'EDF et de l'infime partie des opposants qui, en vertu de leur fonction élective, étaient en position de négocier), confiance qu'elle avait pourtant à construire.

\section{Seconde étape significative}

Une étape autrement importante par ses conséquences sur le cours du débat est la méfiance épistémique qui va surgir à l'égard d'EDF concernant des plans commerciaux suspectés de celle-ci à destination de l'Italie. A strictement parler il s'agit même, là aussi, d'une séquence en plusieurs étapes avec montée pour ainsi dire vertigineuse de la méfiance à l'égard du fournisseur national français d'énergie électrique et interventions significatives dans un sens ou dans un autre des opposants puis intervention décisive de la commission.

Le premier acte décisif de cette séquence est un courrier au président de la Commission d'un des opposants (Denise Raynaud, présidente des «Amis de Vergons») révélant, au demeurant très poliment, l'existence d'un décret (de 1983) dont l'objet était d'approuver un contrat commercial (signé en 1982) entre EDF et son homologue italien, ENEL (Lettre du débat public n ${ }^{\circ} 5$, p. 17). Ce contrat faisait naître le soupçon que la raison véritable de la ligne projetée pourrait bien être, en réalité, de vendre de l'électricité à l'Italie - dont la production est régulièrement déficitaire - vu qu EDF n'avait pas réussi, à ce stade du débat, à convaincre de la nécessité technique de cette ligne à THT pour les seuls besoins de la région PACA.

La raison essentielle de cet échec à convaincre - qu'on peut considérer comme le facteur initial de la séquence que je considère ici - en est étonnante. Ce n'est bien entendu pas qu'EDF n'est pas reconnue compétente en la matière; elle a incontestablement une autorité épistémique auprès de tous les participants au débat. La question est en réalité plus complexe et plus intriquée. On observe en effet que certains des opposants demandent à plusieurs reprises à la responsable du projet, Claudine Nahon, quels sont les besoins en électricité pour les années à venir; or Claudine Nahon ne répond jamais que de façon très évasive, de même qu'elle ne répond que de façon très évasive à un certain nombre de questions d'ordre technique. Le résultat est simplement que les mêmes questions sont reposées plusieurs fois par les opposants avant qu'elle ne finisse par répondre précisément à certaines d'entre elles. Une des raisons possibles de ce silence est que les représentants d'EDF (tous des ingénieurs) ne supposent pas alors que qui que ce soit parmi les opposants soit assez compétent pour qu'il vaille la peine de fournir des réponses circonstanciées. Plus tard, certains des opposants (deux ou trois seulement, en réalité) conquerront auprès des responsables EDF suffisamment d'autorité épistémique par la précision de leurs questions ou le caractère spécialisé des propositions techniques qu'ils seront à même de faire. Mais ce n'est pas encore le cas ici. C'est une autre raison qui est ici déterminante: d'une part, aussi invraisemblable que cela puisse paraître à un néophyte, les responsables d'EDF ne sont pas en mesure de donner une réponse précise à cette question parce que, en la matière, on peut seulement construire des modèles de simulation, que ceuxci, partant de données variables, donnent une fourchette de résultats extrêmement 
étendue et qu'il faut, en outre, faire marcher des ordinateurs un temps considérable pour obtenir les résultats en question, d'autre part que les responsables EDF craignent de perdre toute autorité épistémique, tant peut précisément paraître invraisemblable, à qui n'est pas familiarisé avec les problèmes de simulation, qu'EDF soit incapable de faire des prévisions raisonnables en matière de besoin en électricité au moment même où est projetée une nouvelle installation ${ }^{96}$.

Mais cette incapacité d'EDF à emporter la conviction sur l'élément de base déterminant conduit les opposants au projet à soupçonner des motifs cachés chez les dirigeants d'EDF (dont les représentants lors du débat sont forcément les porte-parole). Le soupçon est a priori d'autant plus raisonnable que le climat est celui de l'annonce de l'ouverture du marché européen à la concurrence en matière de commerce d'électricité et qu'EDF est raisonnablement supposée avoir des visées sur l'Italie. Les dénégations de la responsable du projet EDF selon lesquelles EDF n'a plus aucun plan commercial en direction de l'Italie, le contrat cité étant arrivé à terme dès fin 1985, n'ont aucun effet sur les doutes soulevés, d'autant que Claudine Nahon refuse de révéler le contenu de ce contrat au président même de la Commission, arguant de la confidentialité dudit contrat (Lettre $d u$ débat public $\mathrm{n}^{\circ} 5, \mathrm{p} .18$ ). Ce refus constitue le second acte déterminant de cette séquence. Il apparaît tout à fait déraisonnable aux opposants d'accorder leur confiance épistémique à EDF en pareil cas, i.e. de penser qu'EDF dit réellement la vérité.

L'intervention antérieure d'un des opposants aurait pourtant pu avoir un effet dans un sens tout différent, n'était-ce le rebondissement constitué par la «révélation» de ce décret et le refus de Claudine Nahon de rendre publics les termes du contrat concerné. Un des opposants, Didier Chamonin, militant d'une association d'opposants (Vivre en Haute-Provence) et, pour cette raison, inspirant politiquement la confiance, était en effet intervenu pour dire que l'on devait croire les responsables d'EDF lorsque ceux-ci disaient, en réponse à une question différente, mais pour ainsi dire symétrique - celle de savoir s'il ne serait pas possible de sécuriser l'alimentation en électricité en achetant de l'électricité à l'Italie - que les lignes électriques entre la France et l'Italie qui seraient techniquement proportionnées passaient beaucoup plus au Nord, en direction des villes italiennes très industrialisées comme Milan (sans parler de l'absence d'offre en provenance de l'Italie, vu son propre déficit en énergie électrique $)^{97}$. Il serait, en effet, absurde de faire passer les lignes électriques dans le Parc du Verdon, c'est-à-dire aussi au Sud alors que les centrales d'électricité sont situées sur le Rhône nettement plus en amont et qu'il est tout à fait possible de franchir les Alpes nettement plus au Nord. Chamonin donnait ainsi publiquement raison à EDF: «Pour une fois, je vais être d'accord avec EDF: cette ligne ne servira pas à alimenter l'Italie. L'alimentation

${ }^{96}$ Quoique les enjeux soient moins considérables, le problème est le même que celui que rencontrent les climatologues lorsqu'ils cherchent à simuler l'évolution du réchauffement de la planète: des modèles épistémologiquement a priori tout aussi légitimes donnent des résultats très sensiblement différents.

${ }^{97}$ Claudine Nahon s'était exprimée sur cette question dans une réponse à un courrier, dans la Lettre du débat public, ${ }^{\circ} 4$, du 15 mai, p. 15, puis à nouveau lors de la table ronde du 5 mai 1998 consacrée aux prévisions d'évolution de la demande en électricité en PACA (Lettre du débat public $\mathrm{n}^{\circ} 5$, du $1^{\text {er }}$ juin, p. 8). 
de l'Italie, si elle se fait, se fera par la vallée de la Maurienne» $\left(\mathrm{n}^{\circ} 5\right.$, lettre $\mathrm{du}$ $1^{\text {er }}$ juin, p. 8).

Cette intervention aurait pu être décisive car le militant en question, Didier Chamonin, n'inspirait pas seulement la confiance politiquement parlant ${ }^{98}$ mais aussi épistémiquement parlant (autrement dit, on ne le croyait pas capable de vouloir tromper sur ce qu'il savait). Ce militant était doté aussi d'une véritable autorité épistémique (on croit vrai a priori ce qu'il dit parce qu'on le croit compétent sur ces sujets) ${ }^{99}$. Cette autorité épistémique était peut-être due à des compétences techniques manifestées au cours du débat et dont les participants auraient pu être convaincus $^{100}$. Mais elle était fort probablement surtout due aussi au fait que nombre de participants au débat étaient en mesure de savoir qu'il était ingénieur et que, de plus, sa spécialité était précisément la maîtrise d'énergie: Chamonin était en effet consultant à l'INESTENE (Institut d'évaluation des stratégies sur l'énergie et l'environnement en Europe) et il travaillait pour l'ADEME (Agence de l'environnement et de la maîtrise de l'énergie). Ses compétences n'étaient fort probablement pas supérieures en la matière à celle des ingénieurs EDF, mais elles n'étaient probablement pas non plus inférieures. On ne peut donc même pas dire qu'il y avait une différence d'autorité épistémique entre les uns et les autres. En revanche, les opposants avaient épistémiquement confiance en l'ingénieur de l'INESTENE et pas dans les ingénieurs d'EDF parce qu'ils avaient politiquement confiance dans le premier et pas dans les seconds ${ }^{101}$. Or, la confiance épistémique est ce qui est capital pour qu'un argument soit cru lorsque l'auditoire n'a pas la compétence suffisante pour juger lui-même de la validité de cet argument.

Pourtant l'histoire de la réception de l'argument d'EDF selon lequel ce que vise EDF, c'est bien et c'est bien seulement d'assurer l'approvisionnement en électricité de la Côte d'Azur, n'est pas terminée. L'autorité épistémique de Didier Chamonin et la confiance épistémique (fondée elle-même sur la confiance politique) ne vont pas être suffisantes, en raison du rebondissement que nous avons évoqué. Les doutes soulevés par les Amis de Vergon sont repris après la fin de non-recevoir des responsables EDF par un des militants associatifs les plus déterminés, Jean Gonella (coordinateur régional de la Fédération d'associations FARE-Sud), qui voit dans les raisons invoquées à l'appui de la ligne un «alibi» «masquant» un projet commercial «multinational» qui demande que soient «dévoilés (...) tous les scénarios stratégiques d'adaptation d'EDF à éventuelle fin du service public». Gonella va encore au-delà: «Il faudrait y ajouter les dossiers techniques, cartographiques et économiques des lignes électriques italiennes des

${ }^{98}$ Ce n'est pas en même temps un «élu» et, à la différence par exemple de Raphaël Scipion, il n'est donc pas soupçonnable d'être partagé quant à ses objectifs.

${ }^{99}$ A la différence par exemple, là encore, de Raphaël Scipion, qui n'a pas eu l'occasion de faire reconnaître des compétences techniques particulières.

${ }^{100}$ Il peut les avoir manifestées lors d'un débat légèrement antérieur sur la pertinence des énergies alternatives de type éoliennes ou énergie solaire, sur lequel je reviens plus loin. Pour l'autorité épistémique conquise par D. Chamonin sur les ingénieurs EDF eux-mêmes, voir le point 5 consacré à la «contre-expertise sauvage».

${ }^{101}$ La confiance épistémique dans les experts patentés en général était faible à cette époque depuis leurs silences jugés coupables sur l'ampleur de la catastrophe de Tchernobyl et les dangers encourus par toute l'Europe. 
régions ligure et piémontaise» (Lettre du débat public, $\mathrm{n}^{\circ}$ 7, p. 32). Quatre pages (sur quarante) de la Lettre $\mathrm{n}^{\circ} 11$ lui seront réservées pour qu'il fasse état de tous ses soupçons; entre temps, nombre d'opposants, des personnes ou des associations (le groupe local de Nice de Greenpeace, par exemple), lui auront emboîté le pas.

Le troisième acte déterminant de cette séquence est la découverte d'une coupure de presse d'un journal italien tout récent (il est daté du 2 juillet), envoyée à Jean Gonella en tant que président du Groupe de travail associatif sur la ligne à THT Boutre-Carros; cette coupure de presse indique que le contrat entre EDF et l'ENEL de 1982 vient d'être renouvelé. Le choc est grand car on ne comprend pas que les responsables EDF n'en aient pas fait mention lorsque la question des contrats entre EDF et l'ENEL a été posée, i.e. tout récemment. Pour tous, il y a manifestement eu volonté de tromper par omission, même si ces contrats ne concernent pas spécifiquement la ligne en question. Ce que chacun comprend, c'est que si EDF ne l'a pas fait, c'est qu'elle voulait les cacher, et si elle a voulu les cacher, c'est vraisemblablement parce qu'elle en avait d'autres à cacher ${ }^{102}$. La défiance épistémique à l'égard d'EDF atteint ici son acmé (Lettre du débat public, $n^{\circ} 12$, du 24 août 1998 , p. 20).

Heureusement, n'ayant pas attendu cette détérioration des relations de confiance (épistémique) entre les opposants au projet EDF et les responsables EDF, le président de la Commission, Gérard Porcell, se fondant sur les pouvoirs donnés à la commission, avait demandé dès le 16 juin 1998, à la responsable du projet EDF, Claudine Nahon, que lui soit transmis «sous quinzaine» le contenu du contrat de juin 1982 (Lettre du débat public $n^{\circ}$ 9, p. 32). La destruction, pressentie, de toute confiance épistémique dans les déclarations d'EDF aurait pu avoir de tels effets - le blocage complet du débat - que la Commission s'était sentie tenue de débloquer la situation en imaginant une solution inédite, que la loi n'avait pas prévue mais qu'elle n'interdisait pas non plus: demander à EDF de dévoiler à huis clos ses projets commerciaux avec l'Italie pour les années à venir devant la Commission. La clause du huis clos est facile à comprendre car il est raisonnable de penser que, spécialement à l'approche de l'ouverture du marché de l'électricité au marché de la concurrence, EDF veuille ne pas rendre publics ses plans. EDF dévoilera effectivement le contenu des contrats passés avec ENEL à huis clos et le débat pourra reprendre (réunion de travail de la Commission particulière du 21 août 1998, avec compte rendu dans la Lettre du débat public $\mathrm{n}^{\circ} 14$, du 8 septembre 1998, p. 27). Il s'agit là du quatrième et dernier acte décisif de cette séquence.

On a vu plus haut ce que supposait de confiance réciproque entre les membres de la Commission et les responsables d'EDF cette procédure et ce que supposait encore de confiance de la part des opposants la même procédure. Ce qui reste à

${ }^{102}$ Il s'avère qu'EDF - qui ne projetait nullement n'utiliser la ligne pour fournir l'Italie en électricité (Chamonin avait raison d'approuver EDF sur ce point) - a fait un mauvais calcul tactique concernant son déjà faible «capital confiance»: elle a pensé que révéler l'existence de ces contrats anciens, dont personne n'avait connaissance parmi les participants au débat ou que tous avaient oublié, risquait de conforter les doutes sur ses intentions commerciales. Elle a donc pris le parti de les taire. Mais c'était sans compter sur la possibilité que ces contrats soient retrouvés par des militants vigilants et un brin enquêteurs/inquisiteurs, ce qui a eu des effets désastreux pour EDF en termes de confiance (communication personnelle de J.-P. Puyfaucher). 
comprendre ici, c'est précisément le processus par lequel la Commission a pu conquérir suffisamment la confiance des opposants pour que la procédure s'avère efficace, les intentions d'EDF n'étant plus suspectées et le débat reprenant alors sur de nouvelles bases ${ }^{103}$. Le premier événement décisif sur ce point avait été d'abord la décision prise par la Commission du débat public de demander une contre-expertise, en l'absence d'arguments d'EDF jugés convaincants quant à la nécessité de doubler les lignes électriques existantes; le second est cette décision de «sommer» en quelque sorte EDF de répondre - même si c'est avec une clause de huis clos - aux questions posées sur les contrats à l'Italie. La Commission a conforté lors de cette seconde décision ici la confiance que chacun mettait en elle, mais la clause du huis clos n'a probablement paru acceptable que parce que la Commission avait déjà acquis la confiance par une décision antérieure (que je viens de rappeler) manifestant qu'elle accomplissait avec objectivité et impartialité le rôle purement procédural qui lui était fixé ${ }^{104}$.

$\mathrm{Au}$ terme de cette quatrième étape, il faut bien prendre conscience qu'on est encore très en amont dans le débat tel qu'il doit avoir lieu puisqu'il n'est pas même encore question de ce pour quoi le débat a été mis en place, à savoir s'il faut construire une ligne à THT pour approvisionner en électricité la Côte d'Azur et, dans le cas où la ligne à THT est la bonne solution, quel tracé il faut préférer parmi plusieurs techniquement possibles et économiquement raisonnables. L'absence de «confiance épistémique» mise dans EDF, en même temps que le manque d' «autorité épistémique» des opposants sur les ingénieurs EDF ont grevé lourdement le débat au point de le bloquer. Mais l'autorité décisionnelle de la Commission (elle utilise son pouvoir décisionnel légal dans toute son étendue en décidant la consultation en huis clos) en même temps que la confiance épistémique conquise par la Commission aussi bien sur les opposants au projet que sur les ingénieurs EDF rendent possible le «redémarrage» du débat.

\section{Troisième étape significative: la «contre-expertise sauvage»}

La troisième étape significative du point de vue de la délicate construction de la confiance et de l'autorité à la fois épistémiques et politiques entre les représentants (indirects) du pouvoir et les opposants au projet est constituée par l'impact des résultats de la «contre-expertise» effectuée de manière «sauvage» par un petit

${ }^{103}$ Peut-être serait-il plus juste de dire qu'il n'a plus paru raisonnable de continuer à plaider sur ce terrain (cf. Urfalino [2006]).

${ }^{104}$ C'est aussi Didier Chamonin qui reconnaît le premier à Gérard Porcell de bien mener le débat, donc qui manifeste publiquement sa confiance épistémique: «Je remercie Gérard Porcell de mener ce débat avec une forme d'objectivité que, personnellement, je lui reconnais» (Lettre du débat public, $\mathrm{n}^{\circ} 10$, p. 6). Plusieurs individus ou associations exprimeront la même reconnaissance, dont Jean Gonella lui-même (Lettre du débat public, $\mathrm{n}^{\circ} 11, \mathrm{p} .10, \mathrm{n}^{\circ} 14$, p. 29, etc.). Chamonin dira de façon plus générale, lors de la même table ronde «Je voudrais d'abord dire que, contrairement à d'autres, je suis satisfait de ce débat public»; le contexte montre que le satisfecit s'adresse aussi à EDF qui a accepté de reconnaître des erreurs factuelles importantes, repérées par Chamonin, sur le positionnement des lignes existantes sur une carte et qui a accepté d'étudier une proposition alternative qu'il proposait. D'autre part, Chamonin, comme on l'a vu, a toujours considéré comme tout à fait dénués de fondements, pour ne pas dire absurdes, les doutes sur les véritables intentions commerciales d'EDF (la vente à l'Italie par la ligne projetée). 
groupe d'opposants réunis en groupe de travail. L'idée de cette contre-expertise surgit de ce qu'il est nécessaire de montrer que la première expertise, l'expertise officielle, a été défectueuse sur un plan ou un autre pour qu'une contre-expertise officielle soit décidée par la Commission. Les opposants en question réussissent de fait à montrer qu'il existe apparemment au moins une solution alternative techniquement viable qu'EDF n'avait pas elle-même envisagée, en l'occurrence la construction d'une petite centrale thermique dans l'arrière-pays niçois ${ }^{105}$. La raison pour laquelle effectivement EDF n'y avait pas songé est qu'elle faisait en quelque sorte partie de l'ensemble des solutions a priori exclues pour de simples raisons économiques. C'est en effet une évidence pour les ingénieurs EDF que l'électricité doit provenir des centrales nucléaires de la vallée du Rhône où l'on en produit en abondance. Mais que la solution n'ait pas été explicitement envisagée et discutée suffit à légitimer la demande d'une contre-expertise dont le but est d'examiner si la centrale thermique proposée (ou d'autres solutions alternatives) pourrait résoudre les problèmes électriques au moins aussi bien que la ligne projetée (ce que prétendent les opposants), toutes questions de coût économique mises à part.

Il convient de s'arrêter un peu encore sur cette étape car elle est révélatrice de processus assez complexes et subtils en termes de relations d'autorité et de confiance. En effet, d'un côté, l'équipe d'opposants qui propose l'idée de la centrale thermique le fait avec suffisamment de détails pour qu'elle apparaisse compétente et que cette compétence soit reconnue par l'auditoire pertinent en cette occasion, i.e. non pas EDF mais la Commission, puisque c'est elle qui a autorité pour pouvoir décider une contre-expertise. Mais, d'un autre côté, ce qui est de facto une contre-enquête n'a pas valeur de jure de contre-enquête pour la raison que les auteurs de l'enquête ne sont pas des experts officiels du débat. Autrement dit, pour reprendre les catégories exposées dans la partie précédente, les experts en question n'ont pas vu leur compétence et leur honnêteté certifiées par les instances officielles compétentes, autrement dit par des autorités administratives et donc, en dernière instance, politiques. On peut encore préciser l'analyse: il est douteux que la compétence ne leur ait pas été reconnues dans la mesure où l'on savait certainement, notamment parmi les membres de la Commission,

${ }^{105}$ Denis Chamonin proposera également un système de petits «bouclages» secondaires (rendant inutile la grande boucle qu'aurait constituée la nouvelle ligne avec la ligne littorale et évitant donc le Parc du Verdon), jugé «très intéressant» par les ingénieurs mêmes d'EDF (lettre de Claudine Nahon à Denis Chamonin, du 9 juillet 1998, publiée dans la Lettre du débat public $\mathrm{n}^{\circ}$ 9, p. 35, joignant une appréciation très détaillée de la proposition, ce qui atteste du moment de reconnaissance publique par EDF, pour la première fois, de l'autorité épistémique de Chamonin). Mais ce n'est pas cette proposition qui a eu un effet sur le cours du débat, peut-être parce qu'elle était plus technique et donc plus difficile à apprécier des membres mêmes de la Commission. Il est vraisemblable, en revanche, qu'il y a eu un effet de la confiance épistémique donnée par Denis Chamonin à Claudine Nahon (cf. note précédente) sur l'autorité épistémique pleinement reconnue à Denis Chamonin par Claudine Nahon (en terme de prédisposition à reconnaître cette autorité), de même qu'il y a vraisemblablement eu un effet du même ordre de l'autorité épistémique reconnue à Denis Chamonin sur un point plus élémentaire (le positionnement des lignes existantes) sur la confiance donnée par Denis Chamonin à Claudine Nahon (toujours en terme de prédisposition, en l'occurrence à faire confiance) (cf. note précédente). On peut parler ici d'interaction au sens propre ou d'interaction réciproque, donc de «dialectique de la confiance et de l'autorité» en l'un des sens clairs du terme «dialectique». 
que la compétence des experts improvisés avait été certifiée par des diplômes universitaires de haut niveau ${ }^{106}$. En revanche, ce que l'habilitation officielle est seule censée donner, c'est la confiance épistémique.

Peut-on dire pourtant que cette contre-expertise sauvage n'a eu aucun effet argumentatif autre que procédural? Sûrement pas, dans la mesure où les ingénieurs d'EDF étaient capables de reconnaître la compétence des «experts du cru» ${ }^{107}$ et à même d'examiner ce qui pouvait être (involontairement) biaisé dans leur jugement ${ }^{108}$.

\section{Quatrième étape significative: la contre-expertise officielle}

La Commission du débat public ayant décidé la mise en place d'une contreexpertise comme elle en avait le droit et le pouvoir (financier notamment) ${ }^{109}$, moyennant certaines conditions, la contre-expertise se met effectivement en place et rend au bout de quelques semaines, et dans une certaine précipitation (vu la brièveté des délais impartis et qu'impose le terme du délai fixé par la loi) ses résultats (à savoir que la centrale thermique est en effet une solution technique viable, sous réserve d'un examen plus approfondi) ${ }^{110}$. Là aussi, il faut distinguer plusieurs séquences car ni l'autorité ni la confiance épistémiques ne sont accordés d'emblée par les opposants aux experts pressentis (le cabinet Explicit) pour mener la contreexpertise. Ce n'est pas que leur compétence en tant que telle soit suspectée, mais plutôt sa mise en exercice dans ce cas précis (la performance, pourrait-on dire, si l'on ne craignait de multiplier les distinctions conceptuelles au-delà de ce qui est vraiment nécessaire), dans la mesure où il apparaît difficile de trouver en France des experts en électricité qui ne travaillent pas pour EDF, qui n'ont pas travaillé pour elle ou qui ne seraient pas susceptibles de travailler pour elle, pas d'experts en électricité donc qui peuvent sortir indemnes du soupçon d'avoir un jugement biaisé, même à leur corps défendant. Sans parler de ce qu'il est difficile de se garantir d'actions plus délictueuses où les experts donneraient délibérément, suite à des pressions ou des incitations d'EDF, un rapport favorable à EDF (Lettre du

${ }^{106}$ Ce sont Chamonin et Gonella les principaux inspirateurs de la proposition alternative; on a vu que Chamonin est ingénieur à 1'INESTENE; Gonella est professeur des Universités en physique.

${ }^{107}$ On voit bien que l'opposition experts / profanes est non seulement trop grossière mais peut même manquer complètement de pertinence. L'opposition est entre des experts qui ont autorité pour établir un rapport dont l'Etat tiendra compte et ceux qui ne l'ont pas.

${ }^{108} \mathrm{Il}$ n'y a guère de sens ici à envisager une question de confiance car, si les opposants avaient été tentés de tromper sur les informations qu'ils utilisent dans leurs contre-propositions, la tromperie aurait aisément été découverte par les ingénieurs EDF dans la mesure où ceux-ci avaient un accès direct aux mêmes informations et même à de plus complètes.

${ }^{109}$ A l'époque du débat Boutre-Carros, c'est le maître d'œuvre qui avait en charge de financer expertise et contre-expertise; devant les risques d'interférence, il a été ultérieurement décidé que c'est la Commission particulière qui serait dotée d'un budget et qui le gèrerait elle-même.

${ }^{110}$ Pour des raisons économiques évoquées, EDF ne retiendra pas cette solution, mais réexaminera, en revanche, une solution jugée jusqu'alors techniquement impossible: l'usage des pylônes existants et portant une ligne à 250000 volts (au lieu de 400000 volts), et trouvera une solution moins satisfaisante en terme de quantité d'électricité acheminée que la construction d'une nouvelle ligne, mais plus satisfaisante que le statu quo (la solution satisfait les prévisions à 15 ou 20 ans au lieu de 50 ans) (communication personnelle de Jean-Paul Puyfaucher). 
débat public, $\mathrm{n}^{\circ}$ 7, pp. 11-12). Aucune solution tout à fait satisfaisante n'est d'ailleurs trouvée à ces questions, peut-être parce qu'il n'y en avait pas, sauf à recourir à des experts étrangers (mais qui, cette fois, vu l'ouverture de l'approvisionnement en électricité au marché européen, peuvent a priori être suspectés d'avoir des partis pris nationaux, voire de faire profiter leur pays d'informations sur EDF qu'ils glaneraient au cours de leur expertise) $)^{111}$. La contre-expertise est donc effectuée dans un climat de relative méfiance quant aux résultats qu'elle pourrait donner. Ce qui signifie que si la contre-expertise avait simplement reconduit les conclusions de la première expertise, il est douteux qu'elle ait emporté la conviction. Il n'est pas certain néanmoins que cela aurait été sans effet positif car, comme dans le cas du huis clos entre EDF et la Commission, huis clos qui ne pouvait donner toutes les garanties, le sentiment aurait peut-être été que tout ce qui pouvait être raisonnablement demandé avait été effectué. La dispute aurait peutêtre cessé par une sorte épuisement du stock des questions disponibles et des réponses accessibles ${ }^{112}$. Quoi qu'il en soit, les conclusions de la contre-expertise ne reconduisant pas celles de l'expertise, l'effet immédiat en est que les opposants escomptent un retrait du projet ${ }^{113}$. Légalement toutefois, rien n'y obligeait le gouvernement puisque, en l'état de la loi de 1995, le pouvoir consultatif n'étant pas même reconnu au débat public, le gouvernement n'avait pas à connaître le contenu du débat (ni le détail de son déroulement).

8. Sixième étape significative:

la résistance irréductible de quelques associations d'écologistes

Du point de vue de l'examen des relations de confiance et d'autorité épistémiques et politiques, un dernier fait est particulièrement significatif: il s'agit de l'étonnante résistance de quelques associations d'écologistes - dont celle des «Verts du Var»- aux arguments, notamment aux arguments concernant l'impossibilité de remplacer la solution prévue par EDF par une solution utilisant des sources d'énergie renouvelables (i.e. énergie solaire ou éoliennes) ${ }^{114}$.

Il faut, pour mesurer la signification de la résistance de ces associations d'écologistes, faire un petit retour en arrière. Les ingénieurs d'EDF ont en effet, au cours d'une table ronde spécifique, expliqué qu'il n'était pas possible de satisfaire aux besoins en électricité en recourant à des formes alternatives d'énergie non polluantes du type éoliennes et énergie solaire en raison, d'un côté, d'un régime

${ }^{111}$ On est donc dans une situation, au demeurant très ordinaire, où le choix n'est pas entre des personnes douteuses et des personnes au-dessus de tout soupçon mais des personnes auxquelles on peut faire confiance à des degrés divers.

${ }^{112}$ Cf., à nouveau, Urfalino (2006), dans ce volume, sur la façon dont des discussions aboutissent à un consensus apparent (Urfalino songe toutefois exclusivement aux consensus qui débouchent sur des décisions).

${ }^{113}$ Un effet de la contre-expertise est néanmoins qu'en reconnaissant l'intérêt des contre-propositions de certains opposants (notamment Didier Chamonin et Claude Gonella), elle donne à ces derniers un surcroît d'autorité épistémique.

${ }^{114}$ Voir par exemple la déclaration de Christine Rougemont au nom des «Verts du Var» dans la Lettre du débat public, $\mathrm{n}^{\circ} 15$, p. 36 et la toute dernière déclaration du président des «Verts du Var», Gérard Dauvergne, Lettre du débat public, $\mathrm{n}^{\circ} 16$, pp. 16-17. 
de vents beaucoup trop irrégulier en PACA, de l'autre, d'une disproportion considérable entre ce que l'énergie solaire pourrait fournir et les besoins des entreprises (notamment liées à l'industrie chimique, comme à Fos-sur-Mer), des hôtels, des hôpitaux, etc. (en gros, l'énergie solaire pourrait satisfaire les seuls besoins domestiques) et ils sont revenus plusieurs fois encore sur cette question (Lettre du débat public, $\mathrm{n}^{\circ} 4$, p. 6 et p. 15; $\mathrm{n}^{\circ} 6$, p. 7; $\mathrm{n}^{\circ} 7$, pp. 19-20). Ces arguments vont convaincre progressivement la plupart des opposants sans qu'il soit bien clair si l'intervention de l'un ou l'autre des opposants accréditant les arguments d'EDF a eu un rôle plus déterminant qu'une autre (comme cela a failli être le cas de l'intervention de Didier Chamonin concernant la vente supposée d'électricité à l'Italie) ou si - ce qui est le plus vraisemblable au vu de l'analyse des Lettres - les uns et les autres ont simplement été directement convaincus par les arguments chiffrés précis d'EDF ${ }^{115}$. Nul ne met en doute, de toutes façons, la compétence des ingénieurs EDF; on peut donc dire que ce n'est pas un problème d'autorité épistémique. C'est la bonne foi des ingénieurs seule qui est mise en doute (c'est un problème de confiance épistémique) par quelques associations d'écologistes, notamment les Verts du Var.

Cette réaction est curieuse, car ces associations continuent à défendre coûte que coûte la pertinence des énergies éoliennes / solaires comme alternatives au projet EDF alors qu'aux yeux de tous les autres participants au débat, c'est désormais une évidence qu'il s'agit de pseudo-alternatives. Différentes hypothèses peuvent être énoncées pour expliquer cette résistance. Parmi celles qui reposent sur l'hypothèse que les individus sont rationnels en un sens ou en un autre (éventuellement de manière limitée ou partielle) dans ce qu'ils font, figure l'hypothèse selon laquelle le principe de substitution des énergies éolienne et solaire est considéré jusque là par les Verts comme inviolable et qu'il n'existe pas, dans leur vision du monde, de façon de l'aménager ${ }^{116}$. En l'absence d'un principe mieux adapté, on préfère s'en tenir à une position de principe ${ }^{117}$. Une telle position serait impossible à défendre longtemps sauf pour les Verts à s'isoler complètement et à perdre toute la confiance épistémique qu'on pouvait éventuellement avoir jusque

${ }^{115}$ Le président de l'association Per lou mies vieure (Pour le mieux vivre), Pierre Bibikoff, dit par exemple un jour: «Ce débat laisse trop de place à des alternatives qui n'en sont pas: chacun sait que le solaire et l'éolien ne peuvent fournir la puissance nécessaire» (Lettre du débat public, $\mathrm{n}^{\circ} 8, \mathrm{p} .4$ ). Dès la Lettre suivante, $\left(\mathrm{n}^{\circ} 9\right)$ la Fédération des artisans du bâtiment en prend acte également (p. 9) et le très influent président de la Fédération d'associations FARE-Sud, Jean Gonella, ne parle plus des énergies renouvelables que dans le cadre d'une «synergie de moyens» (p. 9).

${ }^{116}$ Une hypothèse non rationaliste, mais néanmoins légitime, serait d'invoquer par exemple une résistance au changement, hypothèse qu'on peut stipuler de différentes manières encore: paresse intellectuelle, rigidité de comportement, etc. Il n'entre pas dans le cadre du programme de recherche rationaliste que j'essaie de mettre en œuvre d'examiner cette hypothèse. Mais il ne s'agit, bien entendu, que d'un programme de recherche non exclusif des autres; et les hypothèses rationalistes que je formule ne dépassent souvent pas le stade d'hypothèses, en l'état des informations dont je dispose.

${ }^{117}$ Une interprétation particulièrement généreuse pourrait même faire la comparaison avec un type d'attitude épistémologiquement raisonnable et qui consiste - en l'absence d'une théorie meilleure - à conserver une théorie ancienne même lorsque celle-ci a rencontré des observations qui l'infirment, du moment que la théorie rend compte de nombre d'autres faits, a fortiori si, en d'autres occasions, elle permet de découvrir de nouveaux faits ou de nouvelles relations entre des faits. Mais on va voir que cette hypothèse ne tient guère. 
là en eux, tant le refus de ce qui semble s'imposer au simple bon sens semble témoigner de mauvaise foi, s'il ne s'avérait que leur position s'inscrit dans un contexte politique plus vaste, qui conforte le maintien sur une position de principe. Il se trouve en effet que le ministre de l'Aménagement du territoire et de l'Environnement qui aura forcément un avis capital lors des décisions prises par les ministres concernés (le Secrétariat d'Etat à l'Industrie, notamment, rattaché au ministère de l'Economie, des Finances et de l'Industrie) est, à ce moment, Dominique Voynet, i.e. le leader national des Verts. L'espoir est, en effet, que Dominique Voynet empêchera le projet d'être mené à son terme ${ }^{118}$.

Ceci dit, si l'on suppose les individus rationnels, on peut s'interroger sur la façon dont peuvent coexister chez les membres des associations résistantes comme les Verts du Var l'affirmation, pour des raisons de tactique politique, d'une position de principe si contraire au bon sens et la connaissance en quelque sorte «claire et distincte» de ce que la politique défendue est inapplicable. La question mérite d'autant plus d'être posée que les membres de ces associations, par exemple les Verts, ont fait bloc au sens où nul membre des Verts ne s'est distingué en tant que «Vert» pour dire, par exemple, qu'il y avait une position de principe des Verts, qu'il importait de rappeler mais que, en certaines circonstances, il fallait y faire exception, ce qui aurait semblé une position plus rationnelle au sens où elle satisferait à la fois plusieurs critères différents de rationalité: non pas seulement la rationalité adaptative ou «tactique» mais aussi la rationalité logique ${ }^{119}$. Au demeurant, que les Verts du Var comme groupe refusent publiquement des conclusions qui semblent pourtant devoir s'imposer à tous ne signifie même pas que les arguments en question n'ont pas convaincu les membres des Verts du Var en tant qu'individus ${ }^{120}$.

\section{L'issue du débat}

Le caractère le plus remarquable du débat est d'abord, outre le fait qu'à la différence d'une délibération stricto sensu, il ne débouche pas sur une décision, il

${ }^{118}$ Cette hypothèse spécifique a moins de force dans le cadre d'une autre association écologiste qui «résiste» également aux arguments, la Confédération des écologistes indépendants. Celle-ci évoque encore le rôle possible du solaire et des éoliennes lors de la table ronde du 5 septembre exposant les résultats de l'expertise complémentaire (Lettre du débat public $\mathrm{n}^{\circ} 14$, p. 21). On notera que le président de cette Confédération, Maurice Gillard, s'était fait rappeler à l'ordre par le président de la Commission pour avoir enfreint les règles procédurales du débat public: «L'association (...) qui paraît bien mal connaître le cadre législatif et réglementaire de l'actuel débat utilise dans ses écrits des termes pour le moins excessifs, relevant davantage de l'invective, voire de l'injure, que de l'argumentation raisonnée» (Lettre du débat public, $\mathrm{n}^{\circ} 5$, p. 20). Le cas d'une troisième association, le Mouvement écologiste indépendant (Lettre du débat public $\mathrm{n}^{\circ} 15, \mathrm{p} .34$ ), également fermé aux arguments, présente moins d'intérêt puisque celui-ci ne se manifeste qu'à travers un unique courrier de principe venant du président et que celui-ci ni personne de représentatif dans ce mouvement n'a manifestement participé au débat.

${ }^{119}$ Le fait de continuer à se référer à une théorie scientifique générale, même lorsqu'on la sait infirmée par certaines observations, parce qu'on n'en dispose pas de meilleure et qu'elle continue à avoir un pouvoir heuristique, n'empêche nullement de reconnaître l'existence de ces infirmations, donc celles d'«exceptions» à la validité de la théorie.

${ }^{120}$ Sur cette opposition, je ne peux que renvoyer aux travaux de M. Gilbert $(1989,1996)$, dont je fais un autre usage dans la partie conclusive de cet article. Ce type d'explication vaut aussi pour les membres de la Confédération des écologistes indépendants (cf. note supra). 
n'a pas même donné lieu à une proposition de décision puisque le cadre de la loi de 1995 ne le permettait pas. Le président de CPDP a simplement rapporté à la Commission nationale du débat public que le débat avait bien eu lieu. On ne peut pourtant pas dire que le débat a simplement révélé une «résistance» globale de la population devant un projet qui se révélait, au bout du compte, ne pas avoir été suffisamment argumenté (les solutions alternatives techniquement possibles sinon économiquement raisonnables - n'avaient pas été envisagées). La résistance - active et raisonnée - d'une partie de la population, i.e. le fait que certains des opposants ne se soient pas opposés exclusivement brutalement par le refus ou l'invective, mais qu'ils aient argumenté leur opposition et qu'ils aient même suggéré des alternatives techniques, a joué - grâce aux rapports de confiance et d'autorité épistémiques construits au cours du débat - un rôle de stimulant du côté des ingénieurs, de façon à ce que l'issue de la crise politique soit trouvée dans une solution technique innovante ${ }^{121}$. Le reste appartient à l'histoire de la décision, i.e. au niveau des ministères et de leurs délibérations internes et de l'exécution de celle-ci ${ }^{122}$.

\section{CONCLUSIONS ET SUGGESTIONS}

On lit parfois que les procédures du type loi Barnier et la loi concernant la démocratie de proximité sont là pour restaurer l'autorité dégradée du pouvoir politique. Mais un jugement aussi global ne peut avoir de valeur que très approximative. Il ne différencie clairement, en effet, ni l'autorité politique de la confiance politique, ni l'une et l'autre de l'autorité et de la confiance épistémiques, ni l'autorité que l'on détient en vertu de la loi de celle que l'on a en vertu de qualités personnelles reconnues; il ne distingue pas non plus les divers échelons intermédiaires auxquels s'exerce l'autorité politique et où la confiance politique doit être à chaque fois assurée, etc. Il ne dit rien non plus du rôle de l'autorité politique et épistémique, de la confiance politique et épistémique dont jouissent à des degrés divers les leaders d'associations dans les débats. A fortiori laisse-t-il dans l'ombre les ressources considérables qui peuvent être tirées d'instances comme celle constituée par la Commission du débat public, pourvu que ses membres et notamment son président réussissent à gagner la confiance (épistémique) de tous les participants au débat, le maître d'œuvre comme les opposants, et que son président occupe sa fonction avec une autorité décisionnelle personnelle.

$\mathrm{Si}$ la classe politique française prise globalement a largement perdu en quelques années à la fois autorité politique et confiance de la part des administrés, c'est essentiellement, semble-t-il, en raison des affaires de corruption dans le financement des partis (et parfois de corruption personnelle), lesquelles affaires ont été révélées grâce à la détermination d'un certain nombre de jeunes juges

121 Cf. n. 109.

122 Cette histoire n'est pas, à 1'heure actuelle, terminée. En décembre 2005, deux arrêtés ministériels, co-signés les ministères de l'Ecologie, des Transports et de l'Industrie ont, en effet, finalement autorisé la construction de la ligne à THT de 400000 volts à travers le Parc naturel régional du Verdon. Un collectif d'opposants et le Parc lui-même ont alors immédiatement déposé des recours devant le Conseil d'Etat, qui devait prendre sa décision fin juin 2006. 
d'instruction. Ce ne sont évidemment pas des procédures comme la loi Barnier ou la loi concernant la démocratie de proximité qui peuvent faire quoi que ce soit pour restaurer la confiance en la classe politique prise dans son ensemble ${ }^{123}$. Mais, d'un autre côté, certains des leaders associatifs locaux qui ne sont liés en rien à cette classe politique et qui se sont révélés parfois au cours même des conflits que sont censés réguler les débats publics jouissent d'une entière confiance, à la fois politique (du moment que leurs responsabilités associatives n'interfèrent pas avec d'autres responsabilités en tant qu'élus politiques) et épistémique, de la part de leurs concitoyens. Ces leaders - qui sont, en quelque sorte, des «hommes nouveaux»-peuvent, en outre, acquérir une autorité épistémique sur les différents participants au débat et jouer pour cette raison un rôle majeur de régulation de celui-ci, y compris par des interventions peu nombreuses mais en des momentsclés (cf. le cas Chamonin).

Mais c'est cette instance tierce au rôle purement procédural qu'est la Commission, quand elle utilise toute l'étendue de son autorité décisionnelle (ce qui suppose des qualités proprement personnelles, au-delà de ce que donne la fonction) et que les membres qui l'occupent - ou au moins son président - jouissent de la confiance épistémique de tous, qui joue finalement le rôle-clé. Son rôle est cependant loin d'avoir été aussi grand dans tous les débats publics qui ont existé, en partie en raison des qualités personnelles différentes des uns et des autres. Une forme de démocratie de proximité comme la loi Barnier fournit donc a priori des moyens de faire progresser la concertation, par la construction de micro-relations d'autorité et de confiance multiples et complexes. La loi de 2003, en donnant une sorte de pouvoir consultatif à ces débats, rend cohérente une démarche juridique qui ne l'était pas. Mais il est possible de prolonger la réflexion au-delà de ces quelques commentaires.

Un examen attentif des interventions dans le débat qui ont eu un rôle décisif à un moment ou un autre, révèle en effet sans aucune ambiguïté qu'elles sont le fait d'un nombre extrêmement réduit de personnes, de telle sorte que le débat semble à la limite avoir eu lieu entre deux ou trois personnes représentants $\mathrm{EDF}^{124}$, quatre ou cinq opposants non seulement particulièrement militants mais aussi constructifs (c'est-à-dire essentiellement deux opposants) et quelques membres de la commission (c'est le président qui intervient essentiellement). Il faut encore ajouter que - les assemblées générales étant organisées pour que le plus de gens possible puissent énoncer leur avis et entendre des réponses données à leurs questions, et le projet touchant en outre une vaste région - ces assemblées ont été itinérantes (elles ont eu lieu à chaque fois dans des lieux différents), et les tables rondes techniques également, de sorte que non seulement très peu de gens ont joué un rôle déterminant par leurs interventions, mais très peu de gens aussi (guère plus probablement) ont participé à toutes les assemblées générales (sans parler d'avoir assisté à toutes les tables rondes) au sens minimal du terme «participer», i.e. celui de la simple assistance sans intervention (ou de très rares et très brèves interventions). Peu de gens, en effet, se déplacent d'assemblée en assemblée (seuls les plus

${ }^{123}$ Cela ne serait peut-être possible qu'avec l'émergence d'une nouvelle classe politique.

${ }^{124}$ C'est la directrice du projet, Claudine Nahon, qui intervient le plus souvent dans le débat. Ghislain Weisrock, directeur d'énergie Méditerranée, le second représentant d'EDF dans le débat public, joue également un rôle important au niveau des informations techniques. 
militants) pour des raisons aisément compréhensibles: si le coût financier est relativement minime (les distances entre les différentes assemblées sont de l'ordre de quelques dizaines de kilomètres), le coût temporel est considérable, sans parler de l'énergie psychique dépensée ${ }^{125}$.

On pourrait se demander dans ce contexte s'il est bien nécessaire d'organiser des débats de ce genre, forcément très coûteux et dans lequel les débattants effectifs non seulement sont en nombre réduit mais constituent, en outre, intellectuellement une «élite», de sorte que l'on évoluerait vers ce qu'Estlund appelle une «épistocratie» (le gouvernement des plus compétents, à la manière de l'idéal platonicien). Le fait que chaque individu ait l'égale liberté de participer et de s'exprimer ne signifie pas que chacun s'exprime ni même ait forcément envie de s'exprimer. Le sentiment de manquer de compétence pour faire, par exemple, des propositions alternatives, rend disposé à s'en remettre à l'autorité épistémique de quelqu'un en qui on a en outre épistémiquement confiance, autrement dit à lui déléguer (informellement) le pouvoir de faire ces propositions.

Ne vaudrait-il pas mieux, dans ce contexte, organiser un débat entre le maître d'œuvre, la commission - dont l'effectif pourrait peut-être même être réduit - et les quelques militants les plus motivés et les plus compétents? Il existe, après tout, en France même, des structures de concertation qui ressemblent à ce format, ce que l'on appelle les conférences de citoyens (ou de consensus), où sont convoqués quelques personnes supposées représentatives et aux objections desquelles on soumet un projet ${ }^{126}$. Pourtant, vu nos analyses précédentes, le seul énoncé de la question devrait surprendre. C'est qu'il ne suffit en effet pas d'être compétent pour convaincre, il faut être réputé compétent, notamment par les opposants au projet, et jouir de la confiance épistémique (supposant elle-même la confiance politique) des mêmes opposants. Mais il faut aussi conquérir une «autorité épistémique» suffisante auprès du maître d'œuvre et des membres de la Commission, ainsi que leur confiance épistémique. Or non seulement l'identité de ceux qui sont dans cette position n'est pas connue au départ, mais cette position ne semble guère se construire elle-même qu'au cours du débat et comme toute position d'autorité et de confiance, elle est fragile et sujette à renversements ${ }^{127}$. De sorte que,

${ }^{125}$ Les modèles classiques de l'action collective s'appliquent ici: les personnes peuvent calculer, d'une part, que le temps et l'énergie qu'ils dépenseraient à cette «action collective» qu'est la participation au débat, n'en valent pas la peine car leur parole comptera peu dans l'ensemble du débat si tant est qu'ils se sentent compétents pour s'exprimer; et que, d'autre part, d'autres qu'eux seront présents, qui sont plus compétents et dont l'action, si tant est qu'elle réussit, leur profitera de toute façon, qu'ils soient présents au débat ou qu'ils en soient absents. Mais ils peuvent aussi trouver au débat des bénéfices secondaires, y compris celui de s'épanouir au sens de l'idéal républicain animant le courant de la participatory democracy (cf. $\mathrm{II}^{\mathrm{e}}$ partie).

${ }^{126} \mathrm{Cf}$. aussi les structures auxquelles pense J. Bohman (2006) dans ce volume même.

${ }^{127}$ Il y a ainsi, du point de vue de la reconnaissance des opposants par le maître d'œuvre comme par la Commission (au plan de l'autorité comme de la confiance épistémiques), une opposition saisissante entre, d'un côté, le député du Var, Maurice Janetti et le président de la Confédération des écologistes indépendants, Maurice Gillard (l'un et l'autre repris par le président pour leurs «infractions» à la norme d'argumentation, l'un et l'autre n'ayant ni motivé leurs rejets du projet EDF ni avancé aucune contre-proposition argumentée) et, de l'autre, Denis Chamonin et Claude Gonella. S'il est arrivé à ce dernier de manier parfois autant l'invective que Maurice Gillard, il est loin de s'y être limité, argumentant ses soupçons et élaborant des contre-propositions argumentées jusque dans le détail. 
pour coûteux qu'elle soit en termes d'argent pour la communauté et de temps pour beaucoup de personnes, cette structure est peut-être encore la meilleure solution parmi celles dont nous disposons actuellement ${ }^{128}$.

On pourrait bien entendu envisager des solutions à certains égards plus performantes. Sans vouloir me substituer aux spécialistes des politiques publiques (et donc sans rentrer dans le cadre d'une prise en compte des problèmes de réalisabilité) et en envisageant la question uniquement du point de vue de la sociologie générale et de la philosophie sociale, je me contenterai de formuler une unique suggestion qui, au demeurant, s'inspire de suggestions des participants mêmes au débat.

Cette suggestion prend sa source dans le constat d'une perte considérable d'énergie intellectuelle (et de temps) dans le fait de l'existence, en réalité, de trois expertises successives sur la même question (l'expertise officielle, la contreexpertise officieuse, la contre-expertise officielle). On peut, par exemple, penser que l'analyse des besoins et des solutions pourrait être menée sur le modèle des instructions judiciaires dans les pays anglo-saxons, où la cause est instruite en même temps à charge et à décharge par deux instances parallèles. Cela supposerait que les opposants soient dotés d'une enveloppe financière leur permettant de mener leur enquête avec les moyens nécessaires. Cela ne coûterait pas en principe plus cher que d'ordonner une contre-enquête ${ }^{129}$. Mais ce modèle judiciaire n'est peut-être pas encore le plus pertinent puisque ici aucune faute (crime ou délit) n'a été commise et que personne n'est supposé risquer de sortir perdant de la procédure. On peut donc imaginer des procédures plus consensuelles et qui prennent acte de ce que les compétences (qui ne valent, bien entendu, qu'en tant qu'elles sont reconnues et dans un climat de confiance) ne sont pas forcément exactement les mêmes: il peut y avoir une sensibilité aux requêtes des riverains (ce qu'on appelle parfois le «savoir de proximité») versus une sensibilité à l'intérêt général. On pourrait donc envisager en quelque sorte une division réglée du travail, sur le modèle de la communauté scientifique (Kitcher [1990], Thagard [1997]), experts et contre-experts travaillant de concert plutôt qu'indépendamment les uns des autres $^{130}$. Qu'ensuite le gouvernement - ou plutôt tel gouvernement - tienne compte ou non de ces consultations dans ses propres délibérations (stricto sensu) est assurément une question cruciale mais relève cette fois du type d'autorité propre à celui-ci.

On remarquera que l'idée que la coopération intellectuelle est un des types de motifs les plus souvent invoqués à l'appui de la démocratie dite délibérative par des auteurs comme Joshua Cohen (1997b) et David Estlund (1997) ou par les théoriciens du choix rationnel en général (Elster [1998]): le principal argument en

${ }^{128}$ Je dois beaucoup à des conversations avec Jean-Paul Puyfaucher concernant cette appréciation sur la valeur de la procédure du débat public. Je m'accorde, en outre, avec F. Chateauraynaud (2007) sur le fait que, selon les situations, une structure peut être meilleure qu'une autre, du moment qu'elles obéissent à une contrainte d'argumentation (si possible garantie par une instance), de façon à ce que les opinions soient modifiées rationnellement.

${ }^{129}$ Ce genre de requête a été formulé à plusieurs reprises au cours de ce débat - et dès avant même le début officiel du débat public, dans le courrier du député du Var, Maurice Janetti, dont nous avons déjà parlé (Lettre du débat public, $\mathrm{n}^{\circ} 2, \mathrm{p} .11$ ) - et au cours de débats publics ultérieurs.

${ }^{130}$ Voir sur ce point, parmi les théoriciens de la démocratie dite délibérative, Thomas Christiano (1997), p. 247, qui renvoie à l'article fameux de Philip Kitcher (1990). 
faveur de la discussion argumentée - puisque c'est bien de cela qu'il s'agit et non forcément de délibération stricto sensu - c'est que le débat semble le meilleur moyen de faire apparaître les différentes solutions possibles et les différents problèmes susceptibles d'être rencontrés. Une telle coopération n'ôte aucunement au demeurant le rôle de l'autorité épistémique et de la confiance épistémique dans la mesure notamment où les compétences ne sont pas les mêmes. Mais il en est de même dans les communautés scientifiques (Thagard [1997]) $)^{131}$.

On pourrait même espérer se rapprocher d'une communauté au sens de Margaret Gilbert, i.e. telle que les membres de l'une des commissions et les membres de l'autre commission se sentent comme co-engagés les uns avec les autres autour du projet qui serait formulé, y compris s'il s'agit seulement d'un consensus apparent, i.e. par épuisement des objections formulables ${ }^{132}$. Mais si l'on vise la construction d'une telle communauté par le débat, on va au-delà des questions que j'ai entendu aborder ici. Une telle visée, en effet, n'a de sens que dans un cadre républicain; alors que le principe de la discussion argumentée, comme j'espère l'avoir montré, loin d'être spécialement républicain, loin également d'ouvrir une troisième voie entre républicanisme et libéralisme, comme l'a soutenu Habermas (à la faveur d'un glissement de l'idée de discussion publique argumentée à l'idée de délibération) est tout simplement neutre dans le débat libéralisme / républicanisme. En revanche, celui-ci n'est pas neutre du point de vue du développement des Lumières, même si celles-ci doivent faire une place explicite à des relations comme celles d'autorité et de confiance, y compris en matière de connaissance. Or, on peut s'engager à l'égard d'un surcroît de raison non seulement - et non même d'abord - pour des motifs «conséquentialistes» (à la façon, par exemple, d'Elster), mais aussi pour des motifs qu'on pourrait dire - en reprenant l'opposition aujourd'hui habituelle - «déontologiques», i.e. parce que l'on pense que la clarification rationnelle a en soi de la valeur.

Université d'Aix-Marseille I et Institut Jean Nicod, CNRS, Paris

\section{BIBLIOGRAPHIE}

Aristote, 1972, Ethique à Nicomaque, Paris, Vrin.

Berlin I., 1979, «Two concepts of liberty» in I. Berlin, 1979, Four Essays on Liberty, Oxford, OUP, pp. 118-172.

Blatrix C., 1996, «Vers une "démocratie participative”? Le cas de l'enquête publique», in La gouvernabilité, Paris, PUF, pp. 299-313.

Blatrix C., 1997, «Le référendum local, une procédure de démocratie participative? Bilan et perspectives», in D. Gaxie (dir.), Luttes d'institutions. Enjeux et contradictions de l'administration territoriale, Paris, L'Harmattan, pp. 233-269.

${ }^{131}$ Il est dès lors curieux de voir un auteur comme Estlund (1997) récuser sans nuance le poids de l'autorité épistémique dans les débats publics.

${ }^{132}$ Parmi les théoriciens de la démocratie délibérative, c'est Richardson (1997) qui se rapproche le plus de ce genre d'arguments (en se fondant non sur le modèle de M. Gilbert mais sur un modèle proche: celui de R.Tuomela). Bien entendu, la recherche du consensus peut, en tant que telle, être critiquée comme risquant de masquer les rapports d'autorité. 
Bohman J. and W. Rehg, 1997a (ed.), Deliberative Democracy. Essays on Reason and Politics, Cambridge (Mass.), MIT Press.

Bohman J., 2006, «Institutional Reform and Democratic Legitimacy: Deliberative Democracy and Transnational Constitutionalism» in Revue européenne des sciences sociales, 2006.

Bouvier A., 2004, «Dimensions axiologique, épistémologique et cognitive de la délibération publique.Analyse d'un exemple», à paraître in Guillaume Hollard (dir.), $\mathrm{n}^{\circ}$ spécial des Cahiers d'économie politique, 2004, Délibération, débat, démocratie. Version antérieure pré-publiée: «Nature, place et fonction des justifications éthico-politiques dans la dynamique argumentative. L'exemple d'un débat public en Provence-Côte d'Azur (mars-septembre 1998)», Travaux du GEMAS, 2001.

Braud, Ph., 1985, «Du pouvoir en général au pouvoir politique», in Grawitz et Leca, 1985, T. 1, pp. 335-394.

Céfaï, D. et Lafaye, Cl., 2001, «Lieux et moments d'une mobilisation collective - Le cas d'une association de quartier», in D. Céfaï et D. Trom (dir.), Les formes de l'action collective. Mobilisations dans des arènes publiques, Paris, éd. de l'EHESS.

Chateauraynaud, F., 2007, «La contrainte argumentative. Les formes de l'argumentation entre cadres délibératifs et puissances d'expression politiques» in Revue européenne des sciences sociales, 2006.

Chazel, F., 1992, «Pouvoir» in R. Boudon (dir.), Traité de sociologie, Paris, PUF.

Christiano, Th., 1997, «The Significance of Public Deliberation» in Bohman, 1997, pp. 243-277.

Cohen J et J. Rogers, 1983, On Democracy. Towards a Transformation of American Society, London, Penguin Books.

Cohen J., 1997a, «Deliberation and Democratic Legitimacy» in Bohman, 1997a, pp. 67-91.

Cohen J., 1997b, «Procedure and Substance in Deliberative Democracy«, in Bohman, 1997, pp. $407-$ 437.

Coleman J., 1990, Foundations of Social Theory, Cambridge, Harvard Univ. Press.

Crozier M, S. Huntington et J. Watanuki, 1975, The Crisis of Democracy, Report on the governability of democracies to the Trilateral Commission, New York, New York University Press.

Elster J., 1986, «The market and the forum», in J. Elster et A. Hylland (1986), Foundations of social choice theory, Cambridge, C.U.P., pp. repris dans Bohman (1997) pp. 3-33.

Elster J., 1990, Psychologie politique, Paris, PUF.

Elster J., 1994, «Argumenter et négocier dans deux assemblées constituantes», Revue française de sciences politiques, vol. $44, \mathrm{n}^{\circ} 2$.

Elster J., (dir.) 1998, Deliberative Democracy, Cambridge, C.U.P.

Elster J., 1998b, «Deliberation and Constitution Making», in Elster 1998.

Elster J., 2003, [1999], Proverbes, maximes et emotions, Paris, PUF.

Elster J., 2006, «The night of August 4, 1789. A study of social interaction in collective decisionmaking» in Revue européenne des sciences sociales, 2006.

Estlund D., 1997, «Beyond Fairness and Deliberation: The Epistemic Dimension of Democratic Authority, in Bohman (1997a), pp. 173-204.

Fourniau J.-M., 1998, «Observation et analyse du débat public Boutre-Carros. Le Carrousel des Passions et des raisons. Conflit et délibération sur le projet Boutre-Carros», miméo.

Fourniau J.-M., 2006, «L'expérience démocratique Des «citoyens en tant que riverains» dans les conflits d'aménagement» in Revue européenne des sciences sociales, 2006.

Gambetta D. (dir.), 1990, Trust, Oxford, Basil Blackwell.

Gargarella R., 1998, «Full Representation, Deliberation and Impartiality» in Elster (1998).

Gastil J. et W. Keith, «A Nation that (sometimes) Likes to Talk. A Brief History of Public Deliberation in the United States», in Gastil J. et P. Levine (eds), 2005, pp. 3-19.

Gastil J. et P. Levine (eds), 2005, Handbook of Deliberative Democracy: Strategies for Effective Civic Engagement in the 21th Century, San Francisco, Jossey Bass. 
Gilbert M., 1989, On Social Facts, Princeton, Princeton University Press.

Gilbert M., 1996, Living Together. Rationality, Sociality and Obligation, London, Rowman \& Littlefield Publishers.

Goldman A, 1999, Knowledge in a Social World, Oxford, O.U.P.

Goldman A, 2002, Pathways to Knowledge. Private and Public, Oxford, O.U.P.

Grawitz M. et J. Leca (dir.), 1985, Traité de science politique, 4 tomes.

Gret M. et Y. Sintomer, 2002, Porto Alegre, l'espoir d'une autre démocratie. La Découverte, Paris.

Habermas, J., 1976, Après Marx.

Habermas J., 1978, Raison et légitimité. Paris, Payot.

Habermas J., 1986 [1983], «Notes programmatiques pour fonder en raison une Ethique de la discussion» in Habermas, J. (1986), Morale et Communication, Paris, éd. du Cerf, pp. 63-130.

Habermas J., 1987 [1981], Théorie de l'agir communicationnel, Paris, Fayard.

Habermas J., 1992 [1990, 1962], L'espace public (17éd.), Paris, Payot.

Habermas J. 1997a, «Popular Sovereignty as Procedure«, in J. Bohman (1997), pp. 35-65.

Habermas J., 1997b [1992], Droit et démocratie. Entre faits et normes, Paris, Gallimard.

Habermas J., 1998, L’intégration républicaine, Paris, Gallimard.

Habermas J. et J. Rawls, 1997 [1995 et 1996], Débat sur la justice politique, Paris, éd. du Cerf.

Hardin R., 2000, «Conceptions and Explanations of Trust», in D. Gambetta (ed.) (2000), Trust in Society, New York, Russell Sage Foundation.

Hardin R., 2006 «Trust» in Ogien A et L. Quéré, 2006, Les moments de la confiance. Connaissance, affects et engagements, Paris, Economica.

Hardvig J., 1985, «Epistemic Dependence», The Journal of Philosophy, n 82, pp. 335-349.

Johnson J., 1998, «Arguing for Deliberation: Some Skeptical Considerations» in Elster, 1998, pp. 161184.

Kant E., 1947, Qu'est-ce que les Lumières? [1784], Paris, Denoël-Gonthier.

Kitcher Ph., 1990, «The division of cognitive labor», Journal of Philosophy, 1990, pp. 5-22.

Lascoumes P., M. Callon, Y. Barthe, 2001, Agir dans un monde incertain, Paris, Seuil.

Lavau G., et O. Duhamel, 1985, «La démocratie», in Grawitz et Leca, 1985, T. 2, pp. 29-113.

La Lettre du débat public sur le projet de ligne à très haute tension Boutre-Carros, Moser, Malt et Associés, 15 mars 1998-15 septembre 1998.

Lipset S., 1996, «La confiance dans une perspective comparative» in R. Boudon et P. Chaunu (dir.), Autour de Alain Peyrefitte. Valeurs et modernité, Paris, éd. O. Jacob, pp. 153-8.

Manifeste du Parti Socialiste Unifié, 1972, Paris, Tema Editions.

Manin B., 1985, «Volonté générale ou délibération? Esquisse d'une théorie de la délibération publique», Le Débat, février 1985, pp. 72-93.

Manin B. et L. Blondiaux, 2002, «L'idée de démocratie délibérative dans la science politique contemporaine. Introduction, généalogie et éléments critiques», Entretien avec Bernard Manin recueilli par L. Blondiaux, Politix, vol. 15, n 57/2002, pp. 37 à 52.

Bohman J. et W. Rehg (eds), 1997, Deliberative Democracy. Essays on Reason and Politics, Cambridge, Mass., MIT Press.

Memmi D., 1985, «L'engagement politique», in M. Grawitz et J. Leca, T. 3, pp. 310-366.

Michelman, F., 1997, «How Can the People Ever Make the Laws? A Critique of Deliberative Democracy», in Bohman (1997), pp. 145-172.

Monnoyer-Smith (dir.), 2005, L., Nouveaux dispositifs de concertation et formes de controverses: le choix d'un troisième aéroport pour Paris, Rapport final, Université de Technologie de Compiègne.

Ogien, A., 2005, "Confiance” en régime démocratique et en régime totalitaire», in Archives européennes de sociologie, T. XLVI, n³, pp. 445-466.

Pasquino, P., 2006, «Voter et délibérer» in Revue européenne des sciences sociales. 
Pateman, C., 1970, Participation and Democratic Theory, Cambridge, C.U.P.

Pettit Ph., 1998, «Republican Theory and Political Trust», in V. Bratwaite et M. Levi (eds), Trust and Governance (New York, Russell Sage Foundation).

Pettit Ph., 2004 [1997], Républicanisme, Paris, PUF.

Puyfaucher J.-P., 2002, «Concertation, débat public, médiation», Rapport EDF.

Puyfaucher J.-P. (sans date), «Intelligence collective et cohésion sociale: les limites de la médiation et le rôle créateur du débat public», miméo.

Rawls, J., 1987, [1991] Théorie de la Justice, Paris, Seuil.

Rawls, 1995, [2001] Libéralisme Politique, Paris, PUF.

Renaut, A., 2004, La fin de l'autorité, Paris, Flammarion.

Richardson, H., 1997, «Democratic Intentions» in Bohman, 1997a, pp. 349-382.

Rousseau, J.-J., 1964 [1762], Contrat Social in Rousseau, J.-J. Euvres complètes, T. III, Paris, Gallimard, Pléiade.

Stokes, S., 1998, «Pathologies of Deliberation», in Bohman, 1998, pp. 123-139.

Thagard P., 1997, «Collaborative knowledge», Noûs, vol. 31, pp. 242-261.

Urfalino, Ph., 2007, «La décision par consensus apparent. Nature et propriétés», Revue européenne des sciences sociales, 2006.

Weber, M., 2003, [1906], Les sectes protestantes et l'esprit du capitalisme, in Weber, M. (2003), L'éthique protestante et l'esprit du capitalisme suivi d'autres essais, Paris, Gallimard.

Wrong, D., 1979, Power, its forms, bases and uses, Oxford, Blackwell. 